\title{
Case Studies of the Potential Effects of Carbon Taxation on the Stone, Clay, and Glass Industry
}

by M.J. Bock, G.A. Boyd, D.I. Rosenbaum, * and M.H. Ross*

Policy and Economic Analysis Group,

Environmental Assessment and Information Sciences Division,

Argonne National Laboratory, 9700 South Cass Avenue, Argonne, Illinois 60439

December 1992

Work sponsored by United States Department of Energy,

Office of Domestic and International Energy Policy

*Rosenbaum is affiliated with the Department of Economics, University of Nebraska, Lincoln, and Ross Department of Physics, University of Michigan, Ann Arbor. 


\section{CONTENTS}

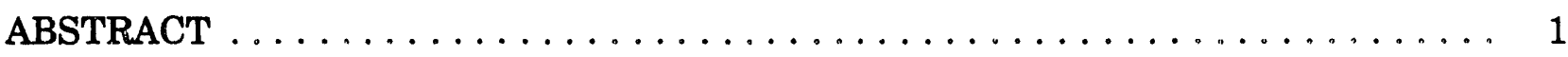

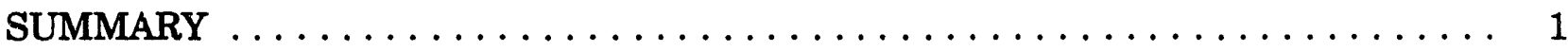

1 INTRODUCTION $\ldots \ldots \ldots \ldots \ldots \ldots \ldots \ldots \ldots \ldots \ldots \ldots \ldots \ldots$

1.1 Current Trends in the Industry $\ldots \ldots \ldots \ldots \ldots \ldots \ldots$

1.2 Energy Use and Energy Use Trends $\ldots \ldots \ldots \ldots \ldots \ldots \ldots$

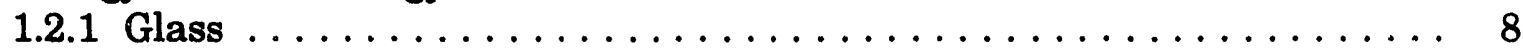

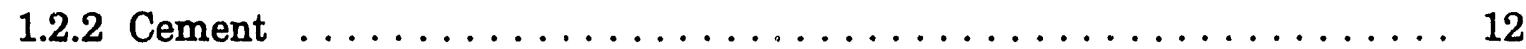

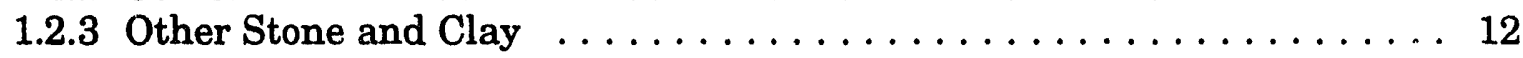

2 CONSERVATION SUPPLY CURVE ANALYSIS $\ldots \ldots \ldots \ldots \ldots \ldots$

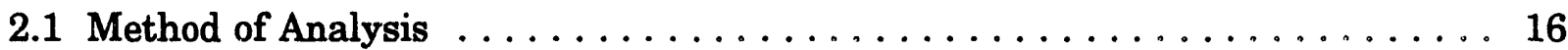

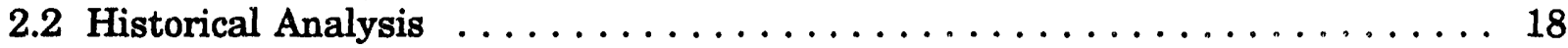

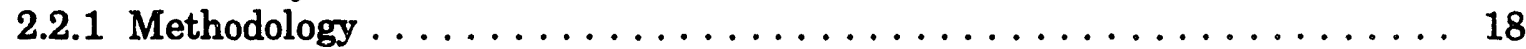

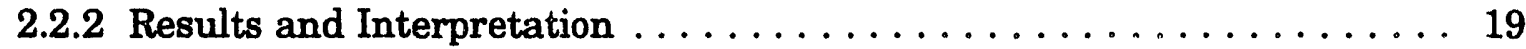

2.2 .3 Conclusions . . . . . . . . . . . . . . . . . . . 24

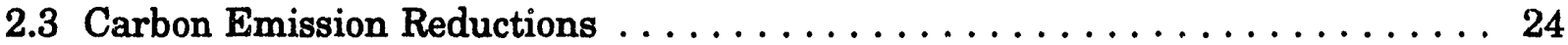

3 PLANT-LEVEL ANALYSIS OF CEMENT M MNUFACTURING . . . . . . . . . 28

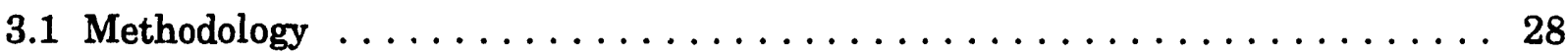

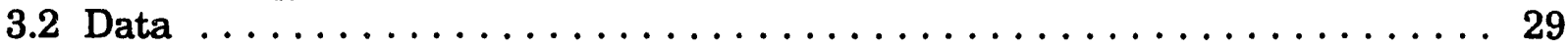

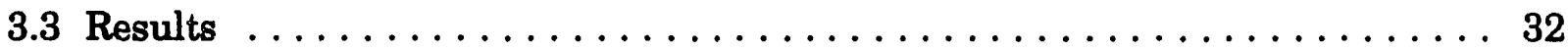

4 ANALYSIS OF FUEL SHARES AND CARBON LOADING IN CEMENT MANUFACTURING $\ldots \ldots \ldots \ldots \ldots \ldots \ldots \ldots \ldots \ldots \ldots$

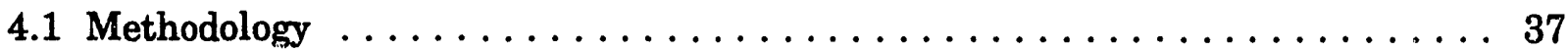

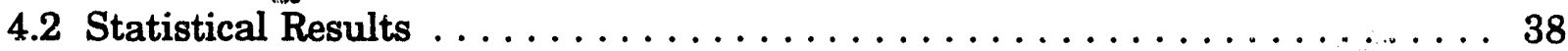

4.3 Effect of Carbon Tax on Average Carbon Content of Fossil Fuel . . . . . . . 39

5 ANALYSIS OF SUPPLY AND DEMAND IN CEMENT

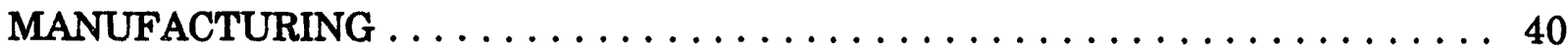

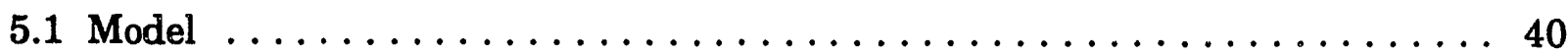

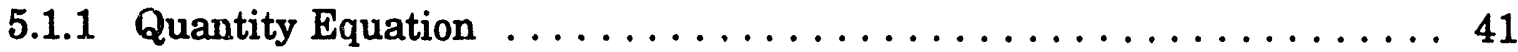

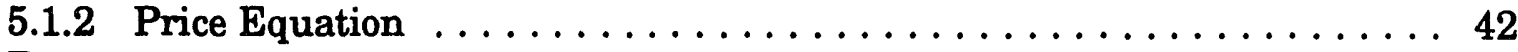

5.2 Data ................................. 42

5.2 .1 Total Capacity $\ldots \ldots \ldots \ldots \ldots \ldots \ldots \ldots \ldots \ldots \ldots \ldots \ldots \ldots \ldots$

5.2 .2 Price ............................... 43

5.2 .3 Quantity ................................ 44

5.2.4 Residential Construction Expenditures . . . . . . . . . . . . . 44

5.2.5 Nonresidential Construction Expenditures $\ldots \ldots \ldots \ldots \ldots \ldots \ldots \ldots \ldots$

5.2.6 Highway Construction Expenditures . . . . . . . . . . . . . . 44 


\section{CONTENTS (Cont.)}

5.2.7 Personal Income $\ldots \ldots \ldots \ldots \ldots \ldots \ldots \ldots \ldots \ldots \ldots \ldots \ldots \ldots \ldots$

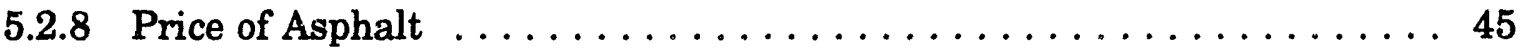

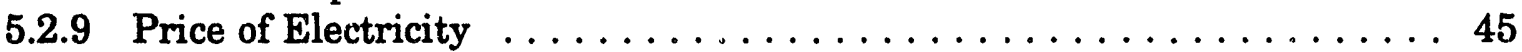

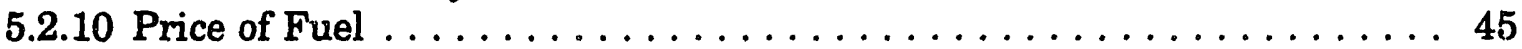

5.2.11 Technology .......................... 45

5.2.12 Herfindahl Index $\ldots \ldots \ldots \ldots \ldots \ldots \ldots \ldots \ldots \ldots \ldots \ldots$

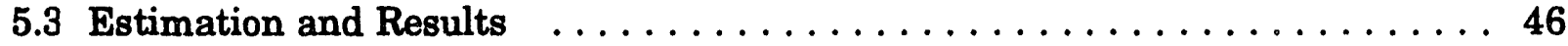

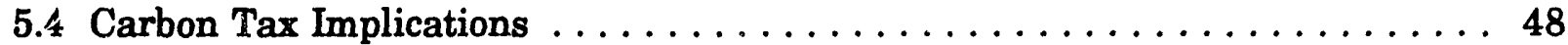

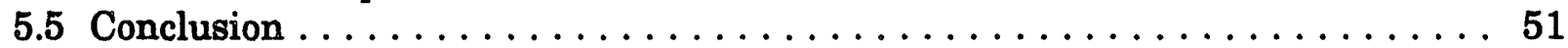

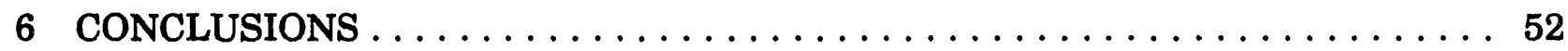

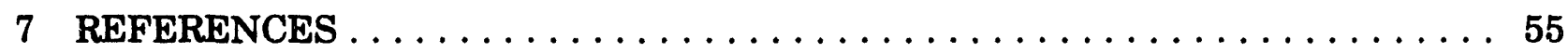

\section{TABLES}

1 Illustrative Energy Prices in the Three Scenarios $\ldots \ldots \ldots \ldots \ldots \ldots \ldots$

2 Sectoral Aggregation and 1985 Summary Statistics $\ldots \ldots \ldots \ldots \ldots \ldots$

3 Percent Cost Increase under a $\$ 100$ Carbon Tax $\ldots \ldots \ldots \ldots \ldots \ldots \ldots$

4 Best-Fit Parameters to Historical Data for the Three Industries $\ldots \ldots \ldots \ldots 18$

5 LIEF Parameters Varied in Historical Forecast ................. 19

6 Reduction in Energy Use under Carbon Taxes .................. 25

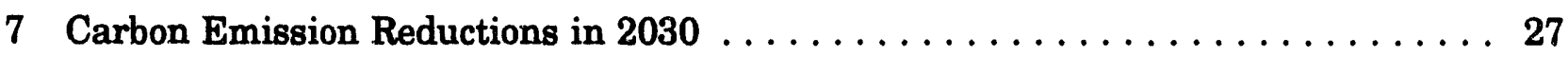

8 Total Value of Shipments and Total Input Usage for the Edited Sample . . . . . 30

9 Edited Sample as a Proportion of Total $\ldots \ldots \ldots \ldots \ldots \ldots \ldots \ldots \ldots \ldots$

10 Total Value of Shipments and Total Input Usage for the Kiln-Level Data . . . . . 32

11 Kiln-Level Data as a Proportion of Total $\ldots \ldots \ldots \ldots \ldots \ldots \ldots \ldots \ldots$

12 Predicted Plant Mean Energy Input Use before and after Carbon Taxes . . . . . . 35

13 Predicted Plant Mean Variable Input Cost Shares before and after

Carbon Taxes ....................................... 35

141985 Btu Fuel Shares for the Three Industries $\ldots \ldots \ldots \ldots \ldots \ldots \ldots$ 


\section{TABLES (Cont.)}

15 Parameter Estimates for Fuel Share Equations $\ldots \ldots \ldots \ldots \ldots \ldots \ldots \ldots$

16 Regional Markets Used in the Analysis $\ldots \ldots \ldots \ldots \ldots \ldots \ldots \ldots \ldots$

17 Relative Fuel Use in the Cement Industry by Year $\ldots \ldots \ldots \ldots \ldots \ldots \ldots$

18 Results of Simultaneous Equation Analysis of Price and Quantity for the Cement Industry . . . . . . . . . . . . . . . . . . . 47

19 Impact of Carbon Taxes on Input Prices and Cement Production Costs . . . . . . 49

20 Prices of Cement and Quantities Sold before and after Carbon Taxes . . . . . . . 50

21 Impact of a $\$ 100$ Carbon Tax on Energy Use in the Cement Industry . . . . . . 52

22 Impact of Carbon Taxes on $\mathrm{CO}_{2}$ Emission Reductions

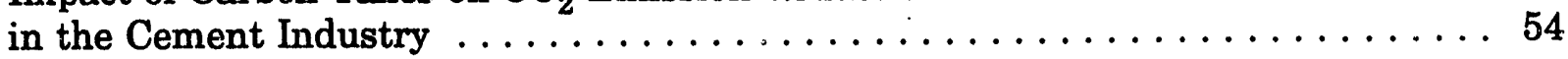

\section{FIGURES}

1 Portland Cement Production Processes . . . . . . . . . . . . . . . . 8

2 Fossil Fuel Use and Prices in the Glass Industry ................ 10

3 Electricity Use and Prices in the Glass Industry $\ldots \ldots \ldots \ldots \ldots \ldots \ldots$

4 Energy Intensity in the Glass Industry $\ldots \ldots \ldots \ldots \ldots \ldots \ldots \ldots \ldots$

5 Fossil Fuel Use and Prices in the Cement Industry . . . . . . . . . . . 13

6 Electricity Use and Prices in the Cement Industry . . . . . . . . . . . 13

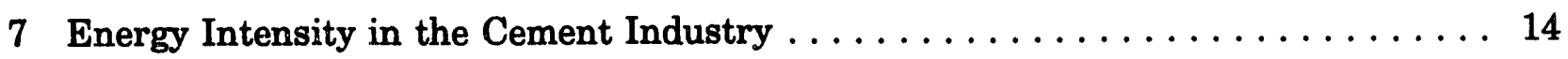

8 Fossil Fuel Use and Prices in the Other Stone and Clay Industry . . . . . . 14

9 Electricity Use and Prices in the Other Stone and Clay Industry . . . . . . . 15

10 Energy Intensity in the Other Stone and Clay Industry ............. 15

11 Electricity Intensity in the Glass Industry $\ldots \ldots \ldots \ldots \ldots \ldots \ldots \ldots \ldots \ldots$

12 Fossil Fuel Intensity in the Glass Industry $\ldots \ldots \ldots \ldots \ldots \ldots \ldots \ldots \ldots$

13 Electricity Intensity in the Cement Industry $\ldots \ldots \ldots \ldots \ldots \ldots \ldots \ldots \ldots$ 


\section{FIGURES (Cont.)}

14 Fossil Fuel Intensity in the Cement Industry $\ldots \ldots \ldots \ldots \ldots \ldots \ldots$

15 Electricity Intensity in the Other Stone and Clay Industry $\ldots \ldots \ldots \ldots 22$

16 Fossil Fuel Intensity in the Other Stone and Clay Industry . . . . . . . . . . 22

17 Step Function Supply Curve for Cement Production $\ldots \ldots \ldots \ldots \ldots$

18 Demand and Supply for Alternative Capacities $\ldots \ldots \ldots \ldots \ldots$ 


\title{
CASE STUDIES OF THE POTENTIAL EFFECTS OF CARBON TAXATION ON THE STONE, CLAY, AND GLASS INDUSTRY
}

by

M.J. Bock, G.A. Boyd, D.I. Rosenbaum, and M.H. Ross

\begin{abstract}
This case study focuses on the potential for a carbon tax ( $\$ 25$ and $\$ 100$ per metric ton of carbon) to reduce energy use and associated carbon dioxide $\left(\mathrm{CO}_{2}\right)$ emissions in three subsectors of the stone, clay, and glass industry: hydraulic cement, glass and glass products, and other products. A conservation supply curve analysis found that (1) opportunities for reducing fossil fuel use in the subsectors are limited (15\% reduction under $\$ 100$ tax) and (2) the relationship between the tax and reduced $\mathrm{CO}_{2}$ emissions is nonlinear and diminishing. Because cement manufacturing produces a significant amount of $\mathrm{CO}_{2}$, this subsector was analyzed. A plantlevel analysis found more opportunities to mitigate $\mathrm{CO}_{2}$ emissions; under a $\$ 100$ tax, fossil fuel use would decrease $52 \%$. (A conservative estimate lies between $15 \%$ and $52 \%$ ). It also confirmed the nonlinear relationship, suggesting significant benefits could result from small taxes (32\% reduction under $\$ 25$ tax). A fuel share analysis found the cement industry could reduce carbon loading $11 \%$ under a $\$ 100$ tax if gas were substituted for coal. Under a $\$ 100$ tax, cement demand would decrease $17 \%$ and its price would increase $32 \%$, a substantial increase for a material commodity. Overall, $\mathrm{CO}_{2}$ emissions from cement manufacturing would decrease $24-33 \%$ under a $\$ 100$ tax and $10-18 \%$ under a $\$ 25$ tax. Much of the decrease would result from the reduced demand for cement.
\end{abstract}

\section{SUMMARY}

This case study focuses on the potential for a carbon tax to reduce energy use and associated carbon dioxide $\left(\mathrm{CO}_{2}\right)$ emissions in three disaggregated subsectors of the stone, clay, and glass industry (standard industrial classification [SIC] code 32): hydraulic cement, glass and glass products, and other SIC 32 products. Two levels of carbon tax are analyzed: $\$ 25$ and $\$ 100$ per metric ton of carbon emitted.

In the first part of the case study, a conservation supply curve (CSC) analysis was performed. This analysis found that the opportunities for reducing energy use in all three subsectors are similar and limited. A 15\% reduction in fossil fuel use would occur under a $\$ 100$ tax. The analysis also found that the relationship between the carbon tax and the 
reduction in $\mathrm{CO}_{2}$ emissions is nonlinear and diminishing. The higher $\$ 100$ tax produces a smaller reduction on the margin. One can infer that successively higher taxes would produce successively smaller marginal gains. This result is consistent with policies that propose only modest carbon taxes.

Because the CSC analysis suggested that the subsectors would not be able to lower their total carbon tax burden very much by lowering emissions, the second part of the case study examined the impact of the carbon tax on the subsector that had the most potential for being severely impacted - cement manufacturing. There are several reasons that the focus was on cement. Some of the reasons a carbon tax would adversely affect the cement industry are:

- Cement manufacturing is highly energy intensive; $37 \%$ of the variable cost at the average cement plant goes toward energy use.

- The cement manufacturing process itself produces a significant amount of $\mathrm{CO}_{2}$, which would be taxed directly under a carbon tax.

- Cement markets are highly regional in nature and subject to cyclical fluctuations in demand from the construction industry.

On the other hand, coal represents a large share of the fossil fuel used in the cement manufacturing sector, so there is a potential for fuel switching.

A series of separate analyses of the cement manufacturing sector examined these issues and came to the following conclusions:

- A plant-level analysis found more opportunities to mitigate $\mathrm{CO}_{2}$ emissions (52\% reduction in fossil fuel use under a $\$ 100$ tax) than the aggregate CSC analysis found. Although a plant-level analysis might be expected to reveal more conservation opportunities, the disparity between the $15 \%$ reduction indicated by the aggregate analysis and $52 \%$ is unexpectedly large, and there is no definitive basis for choosing one estimate over the other. A conservative estimate would lie somewhere between $15 \%$ and $52 \%$. The plant-level analysis also confirmed the nonlinear relationship, which suggests that significant benefits could be achieved as a result of relatively small taxes (32\% reduction under a $\$ 25$ tax).

- A fuel share analysis found that under a $\$ 100$ tax, the cement industry could reduce carbon loading $11 \%$ by substituting natural gas for coal.

- Cement demand would decrease $17 \%$, and its price would increase $32 \%$ under a $\$ 100$ tax. This increase in price is substantial for a material commodity. 
Overall, $\mathrm{CO}_{2}$ emissions from cement manufacturing would decrease $24-33 \%$ under a $\$ 100$ tax and $10-18 \%$ under a $\$ 25$ tax. Ranges are given because the aggregate CSC and plant-level estimates differed. In both cases, much of the decrease in emissions would be a result of the reduced demand for cement because of an increase in price. 


\section{INTRODUCTION}

Because the burning of fossil fuels for energy is responsible for a large share of the carbon dioxide $\left(\mathrm{CO}_{2}\right)$ emitted in the United States, several recent studies of alternative government policies for reducing net greenhouse gas (GHG) emissions in the United States have focused on reducing energy demand (DOE 1989; NRC 1990; EPA 1990; OTA 1991; DOE 1991). Energy demand and emissions of $\mathrm{CO}_{2}$ can be reduced as a result of changes in (1) industrial activity, (2) the composition of production, (3) the forms of energy consumed, and (4) the energy inten ities of manufacturing processes (Ross 1991; DOE 1991; OTA 1991).

This study ass asses the impact of carbon taxes on reducing energy demand and associated $\mathrm{CO}_{2}$ emissions in the stone, clay, and glass industry (standard industrial classification [SIC] 32). Carbon taxes are the most widely studied policy instrument for reducing $\mathrm{CO}_{2}$ emissions (Edmunds and Reilly 1983; EPA 1990; Manne and Richels 1990; Nordhaus 1991; Hogan and Jorgenson 1991; DOE 1991; Goulder 1992). They represent the most economically efficient method to discourage $\mathrm{CO}_{2}$ emissions. By forcing energy prices to reflect $\mathrm{CO}_{2}$ emissions, carbon taxes create incentives to use fuels and processes associated with lower $\mathrm{CO}_{2}$ emissions. Carbon taxes are comprehensive and flexible, allowing the market to choose where $\mathrm{CO}_{2}$ emissions can be reduced in the most cost-effective manner.

The macroeconomic effects of carbon taxes depend on assumptions about how tax revenues are used. The revenues could be used to reduce the federal deficit or fund new programs. Carbon taxes could substitute for other existing federal taxes. This report assumes that no revenues from carbon taxes are rebated to the affected sectors and that the use of these revenues does not affect decision making in these sectors. Evaluation of the schemes for rebating some of the revenues is beyond the scope of this report.

Modeling the impact of carbon taxes can take several forms. One modeling aspect to consider is aggregation and system boundaries. One sector, many sectors, or the entire economy can be modeled. Modeling the entire economy appears to have major advantages; for example, the effects of a carbon tax on interproduct competition, profits, international trade (perhaps), and economic activity in general are taken into account. On the other hand, this comprehensive approach also has a disadvantage. Each of the many connections is modeled in a particular way, and the modeling of each involves important theoretical uncertainties. Modeling the effect of a carbon tax on a single sector has certain advantages; for example, model simplicity is achieved, the level of disaggregation is appropriate, and the opportunity for conservation is analyzed in more detail.

Another modeling dimension involves the choice of top-down (econometric) or bottom-up (engineering or process analysis) approaches. Models for this study employ a simple version of the bottom-up approach and three different econometric approaches. These approaches to forecasting the impact of carbon taxes are presented in separate sections.

In summary, this report examines: (1) application of conservation supply curves, (2) plant-level cross-sectional/time-series analysis, (3) extrapolation of fuel-switching trends, 
and (4) explicit accounting of regional markets in describing industry product supply and demand. These modeling variants are all single-sector models. Therefore, these examinations have been supplemented with qualitative discussions of important interactions with other sectors.

The carbon (C) tax considered is assessed at the point of use. Thus, a tax of $\$ 100$ per metric ton of carbon emitted ${ }^{1}$ results in a cost increase of $\$ 1.47$ for each million Btu of natural gas (which contains $14.7 \mathrm{~kg}$ of carbon) burned at a cement manufacturing plant. Calculated in this way, the fuel cost increase does not reflect the increases in costs experienced by the energy suppliers, which are, perhaps, associated with their energy use. For electricity, the price increase is calculated in terms of energy use at the supplier power plants. Increases in prices of other factors of production caused by the tax are not modeled in this study. The increases are relatively small for energy-intensive industries.

For purposes of illustration, Table 1 shows average fossil fuel prices under the two carbon tax rates studied here, $\$ 25$ and $\$ 100$ per metric ton of carbon. For the "base case" columns in Table 1, it is assumed that the fossil fuel mixture is the same as that in the National Energy Strategy (NES) base case (EIA 1990). The NES provides a reference longrange energy forecast and a range of policy "excursions" or scenarios. It covers all aggregate energy supply and demand activities to the year 2030, but it does not model individual industries, as is done in this report. It does provide an important context for discussing longrange energy supply issues, like price and fuel mix. One of the major determinants of carbon taxes as indirectly imposed on energy consumers is the carbon intensity of purchased electricity. For this report, the chosen scenario represents an aggressive reduction in the carbon intensity of electricity supply (i.e., the fossil fuel that is burned to generate electricity), because this scenario would be more likely in the event of a carbon tax program. Thus, the other columns in Table 1 show electricity prices under a $\$ 25$ and a $\$ 100$ carbon tax for a scenario that represents aggressive reduction in the carbon intensity of the electricity supply mix - the NES excursion scenario (DOE 1991/1992).

\subsection{CURRENT TRENDS IN THE INDUSTRY}

The stone, clay, and glass industry (SIC 32) was selected for study because it has the fourth highest energy intensity of the major U.S. industrial sectors, after the petroleum, paper, and steel sectors, two of which have been examined in other case studies in this series. SIC 32 accounted for $6.5 \%$ of U.S. manufacturing energy demand for heat and power in 1988 (EIA 1991).

Perhaps the outstanding feature of the economic status of the industries in SIC 32 is the maturity of most of the markets. This characteristic is typical of energy-intensive

1 The tax is taken to be in 1990 dollars, and carbon emissions are in metric tons ( $t$ or tonnes). The tax is referred to simply as a $\$ 100$ (or $\$ 25$ ) tax throughout this report. 
TABLE 1 Illustrative Energy Prices in the Three Scenarios

\begin{tabular}{|c|c|c|c|c|c|c|}
\hline \multirow[b]{2}{*}{ Year } & \multicolumn{3}{|c|}{$\begin{array}{l}\text { Average Fossil Fuel Price } \\
\quad\left(1982 \$ / 10^{6} \mathrm{Btu}\right)\end{array}$} & \multicolumn{3}{|c|}{$\begin{array}{l}\text { Electricity Price } \\
\left(1982 \$ / 10^{6} \mathrm{Btu}\right)\end{array}$} \\
\hline & $\begin{array}{l}\text { Base } \\
\text { Case }^{\mathrm{a}}\end{array}$ & $\$ 25 / t$ & $\$ 100 / t$ & $\begin{array}{l}\text { Base } \\
\text { Case }^{\mathrm{a}}\end{array}$ & $\$ 25 / t$ & $\$ 100 / t$ \\
\hline 1980 & 2.77 & 2.77 & 2.77 & 10.70 & 10.70 & 10.70 \\
\hline 1985 & 3.09 & 3.09 & 3.09 & 13.10 & 13.10 & 13.10 \\
\hline 1990 & 2.20 & 2.20 & 2.20 & 11.01 & 11.01 & 11.01 \\
\hline 1995 & 2.49 & 2.49 & 2.49 & 10.88 & 10.88 & 10.88 \\
\hline 2000 & 3.14 & 3.52 & 4.64 & 11.31 & 12.33 & 15.82 \\
\hline 2005 & 3.78 & 4.12 & 5.27 & 11.80 & 12.94 & 16.37 \\
\hline 2010 & 4.42 & 4.81 & 5.96 & 12.28 & 13.44 & 16.92 \\
\hline 2015 & 4.69 & 5.04 & 6.22 & 12.33 & 13.45 & 16.82 \\
\hline 2020 & 4.96 & 5.35 & 6.53 & 12.38 & 13.47 & 16.72 \\
\hline 2025 & 5.13 & 5.48 & 6.67 & 12.43 & 13.46 & 16.55 \\
\hline 2030 & 5.30 & 5.70 & 6.90 & 12.47 & 13.45 & 16.38 \\
\hline
\end{tabular}

a Base case: U.S. Department of Energy (DOE). Energy Information Administration (EIA), personal computer integrated model (PC-IM) base case (run 306), July 20, 1990. Data on the carbon intensity of electricity supply are from the NES excursion scenario (Koomey et al. 1992).

Source: Hwang and Ross (1992).

industries. From an energy perspective, a factor of interest is the amount of manufactured material invulved, even though such data are not available for all sectors. According to the U.S. Department of Commerce (DOC), cement consumption (in tonnage) has grown perhaps $0.3 \%$ per year in the past 20 years. In the early 1970 s, cement consumption peaked at 91 million tons; in the late $1980 \mathrm{~s}$, it peaked again at 94 million tons. This saturation in materials use was not a result of increasing imports or of simply replacing older materials with newer ones; it was a result of the ongoing reduction in the weight of materials used per constant dollar of economic activity (Williams et al. 1987). This phenomenon has been called dematerialization (Herman et al. 1989). According to DOC's Current Industrial Report, consumption of flat glass is growing more rapidly than consumption of cement (in tonnage), but the average growth rate of about $2.0 \%$ per year is still slower than the gross national product (GNP) growth rate. The declines in consumption (in tonnage) of clay bricks and of glass containers during this period were also, in part, a story of market loss to competing materials. Production of bottles declined from a local peak of 14.0 million tons in 1978 to a temporary peak of 11.0 million tons in 1989 and is now 10.5 millinn tons. Production of clay bricks fell from 8.7 million tons in 1977 to 7.1 million tons in 1988.

This market maturity does not imply that products or production processes are static. Although these industries are not characterized by overall growth, many important changes have been taking place in both products and processes. Sophisticated coated window glass 
is gaining a broad market share. Thinner bottles are being produced. In the cement industry, new processes are being adopted. Figure 1 shows the increasing share of the dry process and the increasing average kiln size in the cement industry. Because these are slow-growth or no-growth, capital-intensive industries, however, capital-related changes are gradual.

Another i-nporiant characteristic of some of these industries has been the fact that there has been little competition from imports. Glass, cement, concrete products, clay bricks, and gypsum wallboard are products that tend to be consumed near the point of production. However, cement imports rose to $19 \%$ of consumption in 1987 (11\% in 1991). Flat glass exports typically exceed imports, but growing imports were of concern in the early $1980 \mathrm{~s}$, and special duties were applied. (The trade balance in flat glass has shifted back since then.)

\subsection{ENERGY USE AND ENERGY USE TRENDS}

For this discussion, SIC 32 is divided into three subsectors: glass, cement, and other stone and clay. Data on the SIC components and energy use by these industries in 1985 are shown in Table 2.

\subsubsection{Glass}

The histories of energy consumption and energy prices in the glass subsector over the 1958-1985 period are shown in Figure 2 for electricity and Figure 3 for fossil fuels. The basic patterns were similar for all three subsectors discussed in this report: fossil fuel use

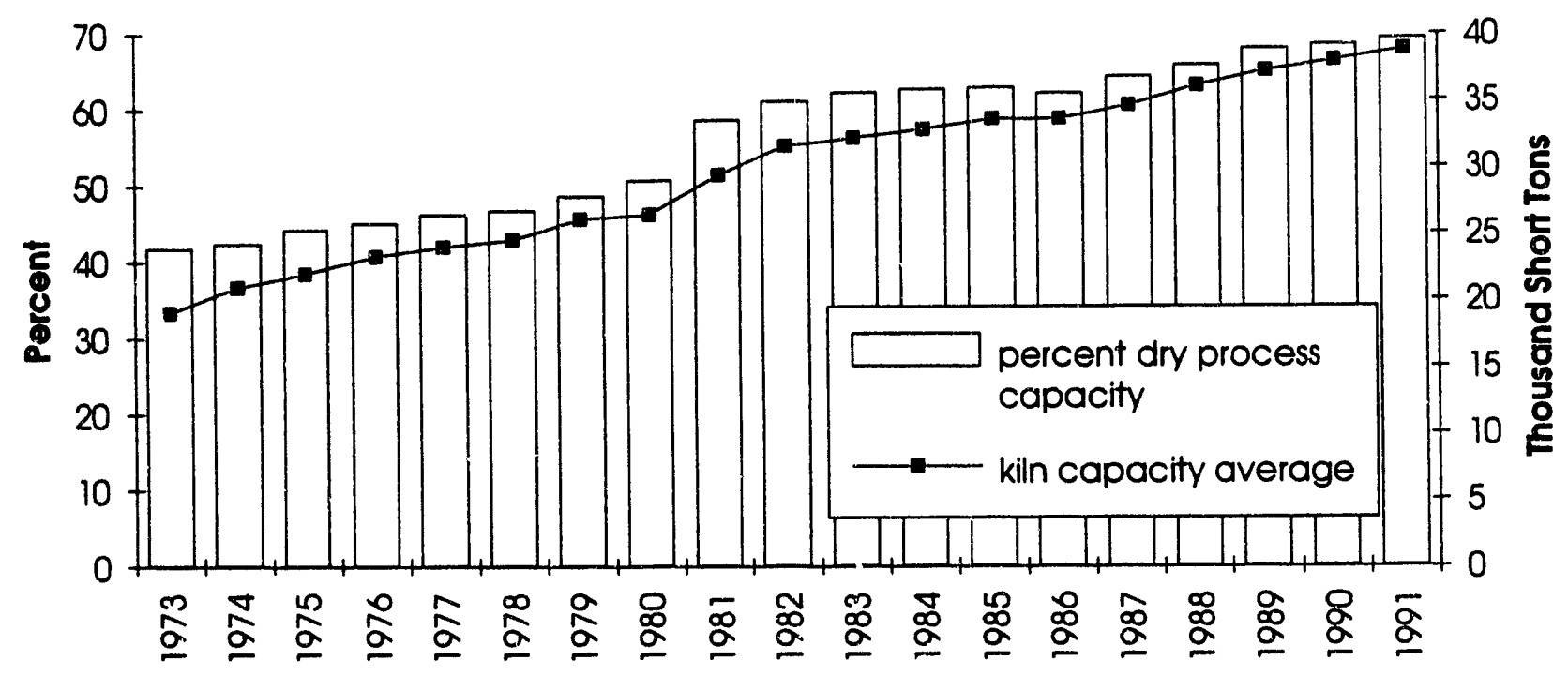

FIGURE 1 Portland Cement Production Prccesses (Source: PCA Plant Information Summary) 
TABLE 2 Sectoral Aggregation and 1985 Summary Statistics

\begin{tabular}{|c|c|c|c|c|c|}
\hline \multirow[b]{2}{*}{ Industry } & \multirow[b]{2}{*}{ SIC } & \multicolumn{2}{|c|}{$\begin{array}{l}\text { Energy Consumption } \\
\qquad\left(10^{12} \mathrm{Btu}\right)^{\mathrm{a}}\end{array}$} & \multicolumn{2}{|c|}{$\begin{array}{l}\text { Energy Intensity } \\
\left(10^{3} \mathrm{Btw} / 1982 \$\right)^{\mathrm{b}}\end{array}$} \\
\hline & & Electricity & Fossil Fuel & Electricity & Fossil Fuel \\
\hline Glass & $\begin{array}{l}321,322 \\
323\end{array}$ & 30.4 & 184.4 & 2.35 & 14.24 \\
\hline Cement & 324 & 32.1 & 298.4 & 8.04 & 74.70 \\
\hline $\begin{array}{l}\text { Other } \\
\text { stone } \\
\text { and clay }\end{array}$ & $\begin{array}{c}325,326 \\
327,328 \\
329\end{array}$ & 50.0 & 317.7 & 1.47 & 9.33 \\
\hline
\end{tabular}

increased; then, starting in the early 1970 s, it decreased, roughly coinciding with an increase in fossil fuel prices. (There was an extraordinary price increase of a factor of six or more from the valley in 1971 to the peak in 1982.) The price increase was strongly signaled by the natural gas shortages of 1970 and 1971 (natural gas is the dominant fuel in this industry). Electricity consumption increased more dramatically than fossil fuel consumption in the period through the early 1970s. It stagnated (rather than decreasing substantially, like fossil fuel use), starting perhaps in the mid 1970s, a time that roughly coincided with the increase in the price of electricity.

More important than energy consumption from an analytical perspective is the history of energy intensity (i.e., energy use per unit of output). In this report, energy use data are from DOC's National Energy Accounts (NEA 1988), and output data are deflated gross output data from the U.S. Bureau of Labor Statistics (BI $\left.\mathrm{B}_{\mathrm{S}}\right)$. The glass industry energy intensities (Figure 4) do not cloarly exhibit the characteristic behavior seen in most manufacturing sectors (falling fossil fuel intensity before the early $1970 \mathrm{~s}$, followed by a faster fall [barely significant for glass]; and rising electricity intensity before the early 1970s, followed by roughly constant intensity thereafter). The last-mentioned behavior (or any change in trend) is not observed for glass. The reason may be that electrification continues to be strong in the glass industry.

It is also likely that the deflaced gross output series does not reflect tonnage of glass produced. Glass bottles account for most of glass production on a tonnage basis. Two major developments reduced the weight of glass per bottle duing the period: the decline in use of recyclable bottles, which are heavier, and the introduction of more controllable press and 


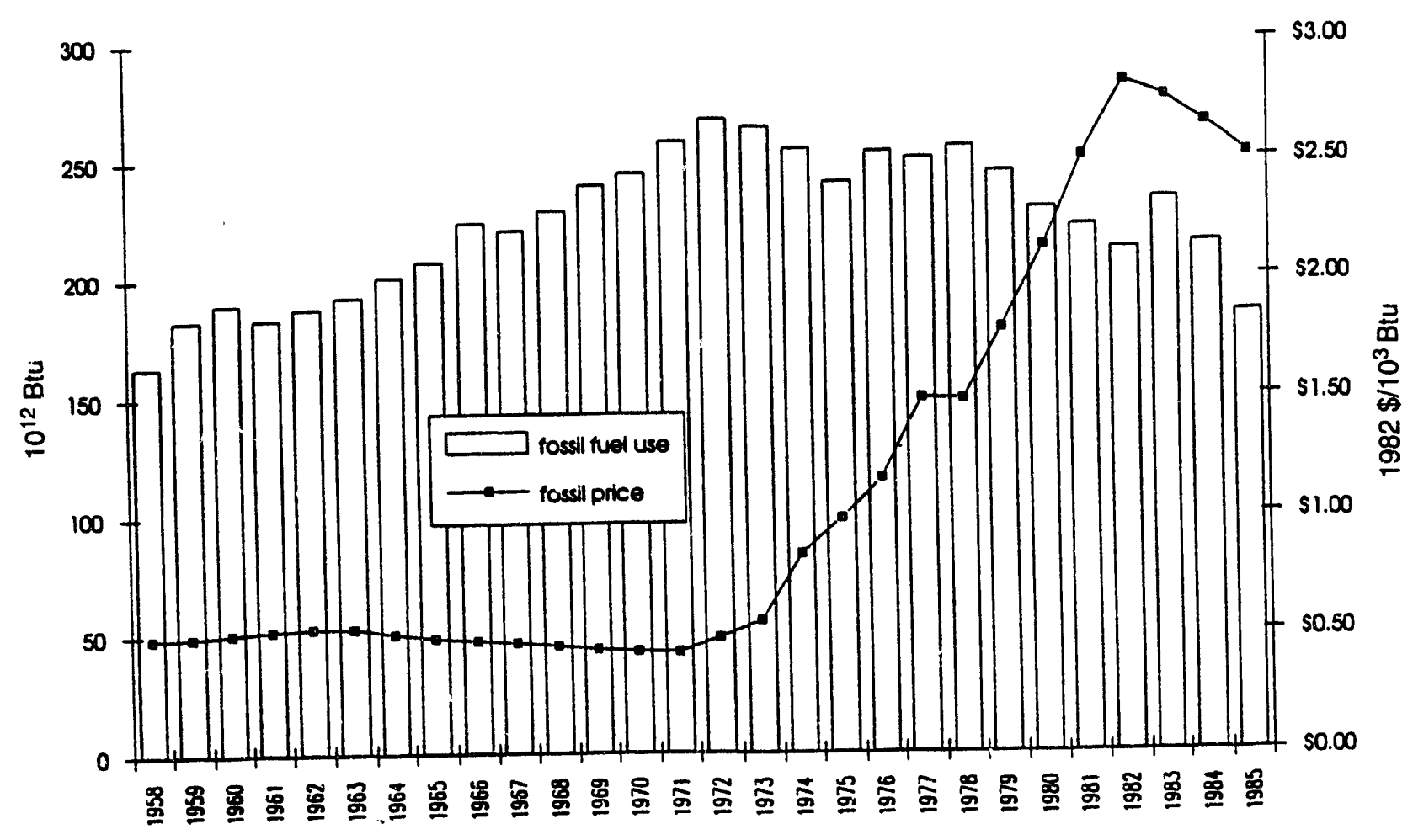

FIGURE 2 Fossil Fuel Use and Prices in the Glass Industry (Source: NEA 1988)

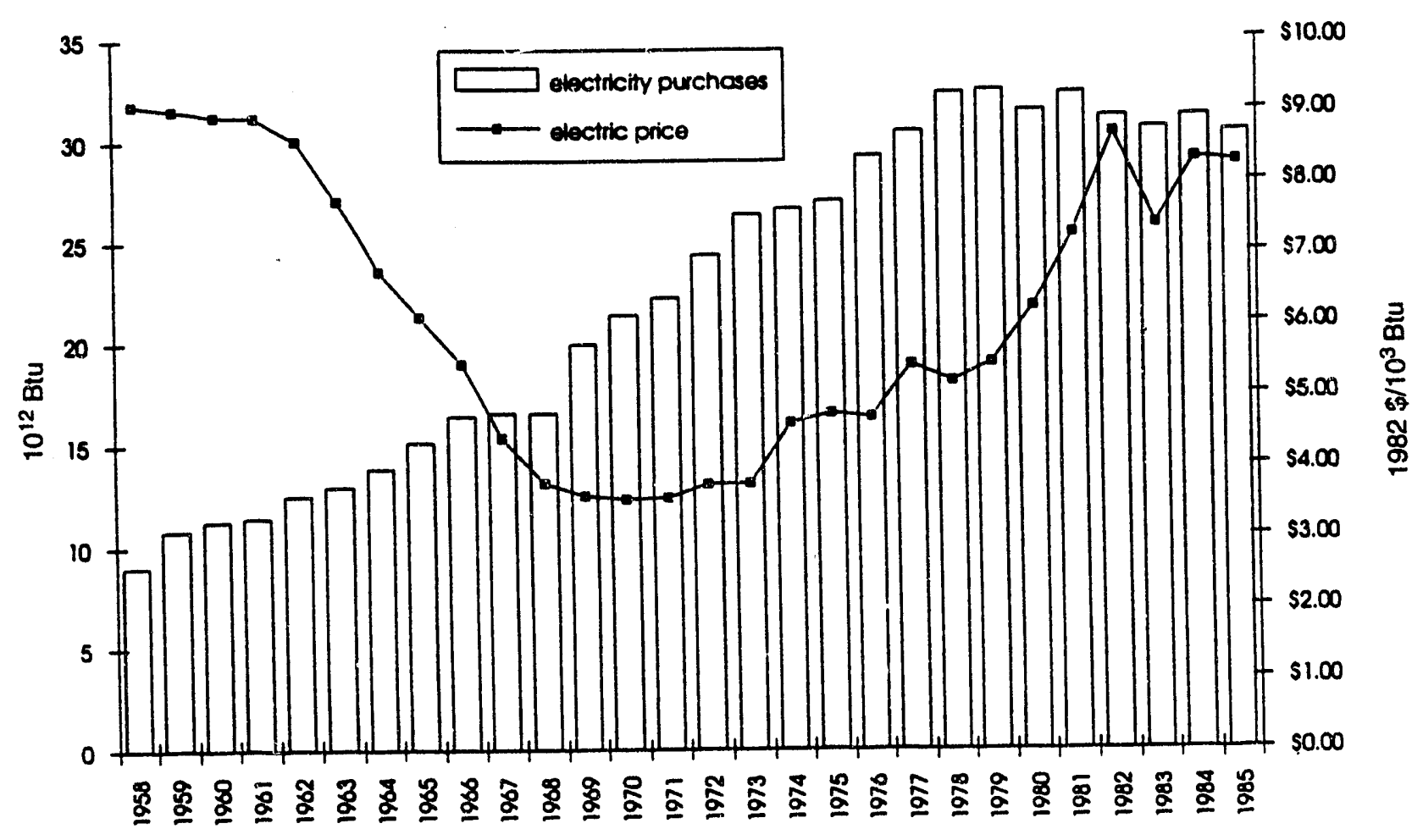

FIGURE 3 Electricity Use and Prices in the Glass Industry (Source: NEA 1988) 


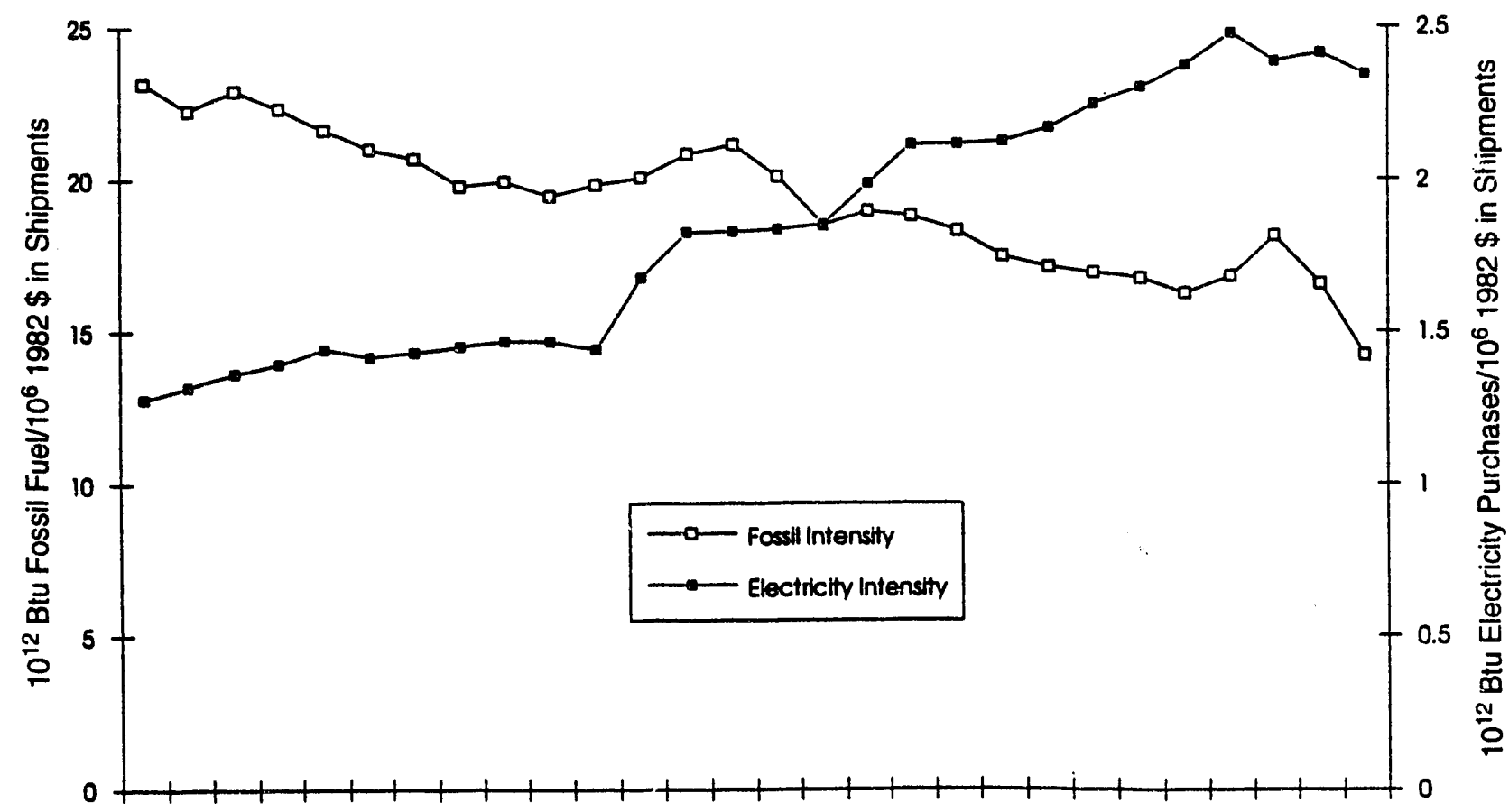

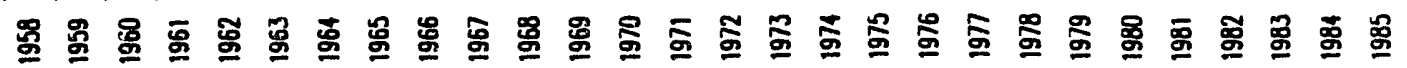

FIGURE 4 Energy Intensity in the Glass Industry (Source: NEA 1988)

blow processes for creating bottles, resulting in thinner walls in cases where strength is less important. Shifting the definition of intensity from gross output to tonnage would reduce the early intensities shown in Figure 4 so that a change in rate of decline in energy intensity in the 1970s would become evident. Unfortunately, an adequate data series for tonnage is not available.

It is perhaps not widely known that $\mathrm{CO}_{2}$ is emitted from the processing of materials in several SIC 32 industries other than cement. Glass-making and lime-making, as well as cement-making processes, emit $\mathrm{CO}_{2}$ in addition to the $\mathrm{CO}_{2}$ emitted from burning fossil fuels (Figure 2). Processing emits about 0.05 tonne of carbon (in $\mathrm{CO}_{2}$ ) per ton of glass produced, 0.14 tonne per ton of cement, and 0.20 tonne per ton of lime. ${ }^{2}$ Only in the cement industry does the share of $\mathrm{CO}_{2}$ emitted from the process represent a significant percentage of total $\mathrm{CO}_{2}$ emissions: roughly one-half of the $\mathrm{CO}_{2}$ is emitted from the process and one-half is emitted from burning fuel. The $\mathrm{CO}_{2}$ emitted from lime production is about one-fourth from the process, and the $\mathrm{CO}_{2}$ emitted from glass production is about one-fifth to one-sixth from the process, owing to the small contribution that the manufacturing of these products makes to total sector output.

2 A ton is a short ton (2,000 pounds). 


\subsubsection{Cement}

The corresponding histories for the cement manufacturing subsector are shown in Figures 5, 6, and 7. Energy use follows the standard patterns just discussed. The increased rapidity of decline in fossil intensity starting in the early 1970s is clear, as is the saturation in electricity intensity (Figure 7). The success that the industry had in limiting the increase in fossil fuel prices by switching from $40 \%$ coal use in the early 1970 s to $90 \%$ coal use in the mid 1980s (Btu basis) can be seen in Figure 5. Because of this switch, the average fossil fuel price increase was limited to less than $\$ 1.00$ per thousand Btu. In other sectors over a similar time period, the average fossil fuel price increased about $\$ 2.00-\$ 2.50$ per thousand Btu.

The cement manufacturing process gradually improved over this whole period, with increasing kiln size and a shift from a wet to a dry process (Figure 1). The fuel intensity reduction per ton was substantially less than that shown in Figure 7, however. On a tonnage basis, fuel intensity declined about $30 \%$ (it declined about $50 \%$ on a gross-output basis) from the early 1960 s to the mid 1980 s.

\subsubsection{Other Stone and Clay}

The other stone and clay subsector also displays the standard energy patterns (Figures 8, 9, and 10). This industry is the aggregate of diverse sectors: manufacturers of bricks, tile, refractories (heat-resistant products), ceramic (plumbing, kitchen, and electrical) products, concrete blocks and other concrete shapes, ready-mixed concrete, lime, gypsum wall board, cut stone, abrasives, mineral wool, and other nonmetallic mineral products. An especially interesting segment is the lime industry, because $\mathrm{CO}_{2}$ is emitted from the raw material in producing lime as well as from the fuels burned. More than 0.2 tonne of carbon (in $\mathrm{CO}_{2}$ ) is emitted from the raw materials per ton of lime produced, so carbon taxes could have a major impact on the lime industry. However, it is a small segment of the other stone and clay subsector, accounting for $\$ 720$ million of $\$ 42$ billion in shipments in 1990 . 


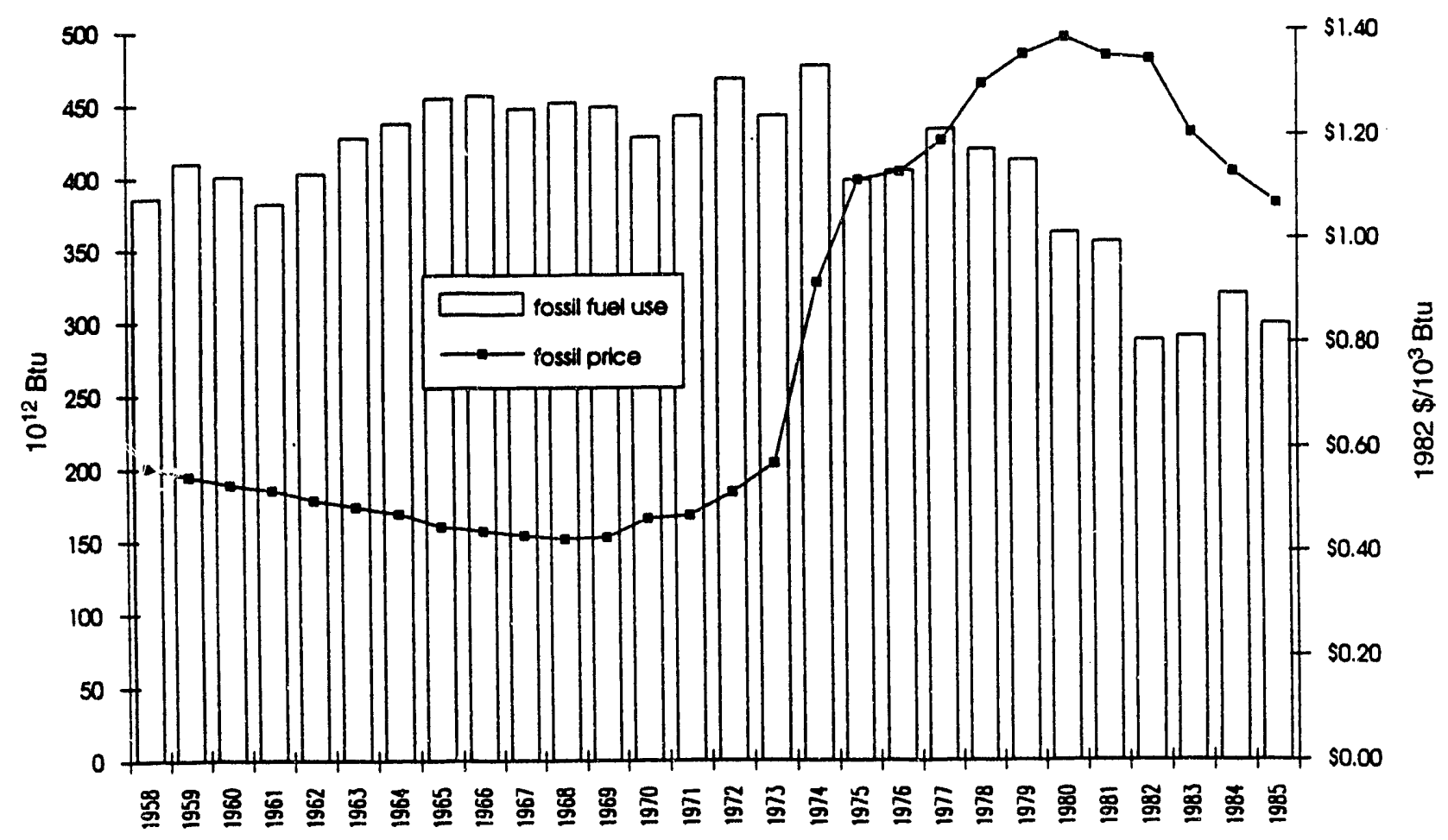

FIGURE 5 Fossil Fuel Use and Prices in the Cement Industry (Source: NEA 1988)

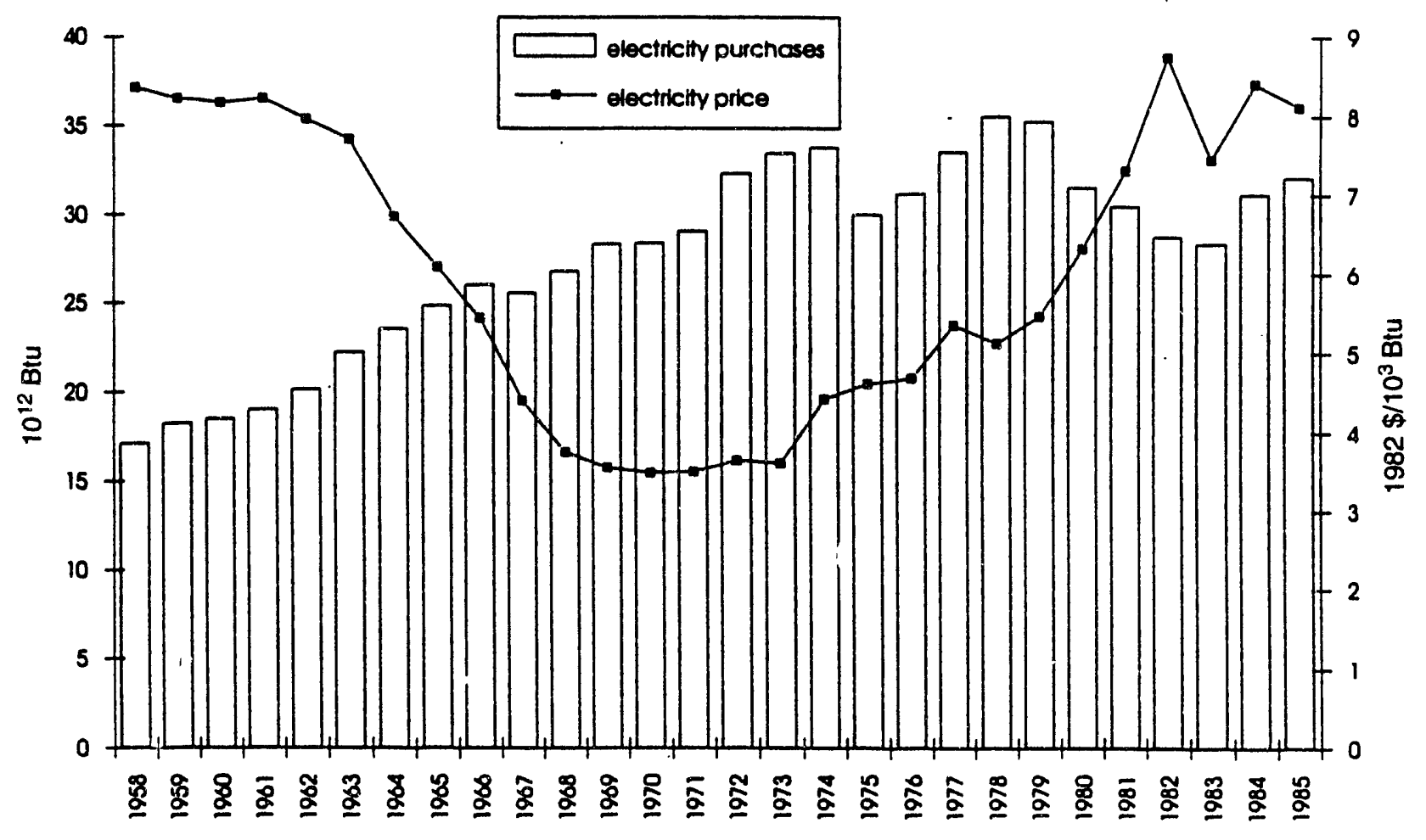

FIGURE 6 Electricity Use and Prices in the Cement Industry (Source: NEA 1988) 


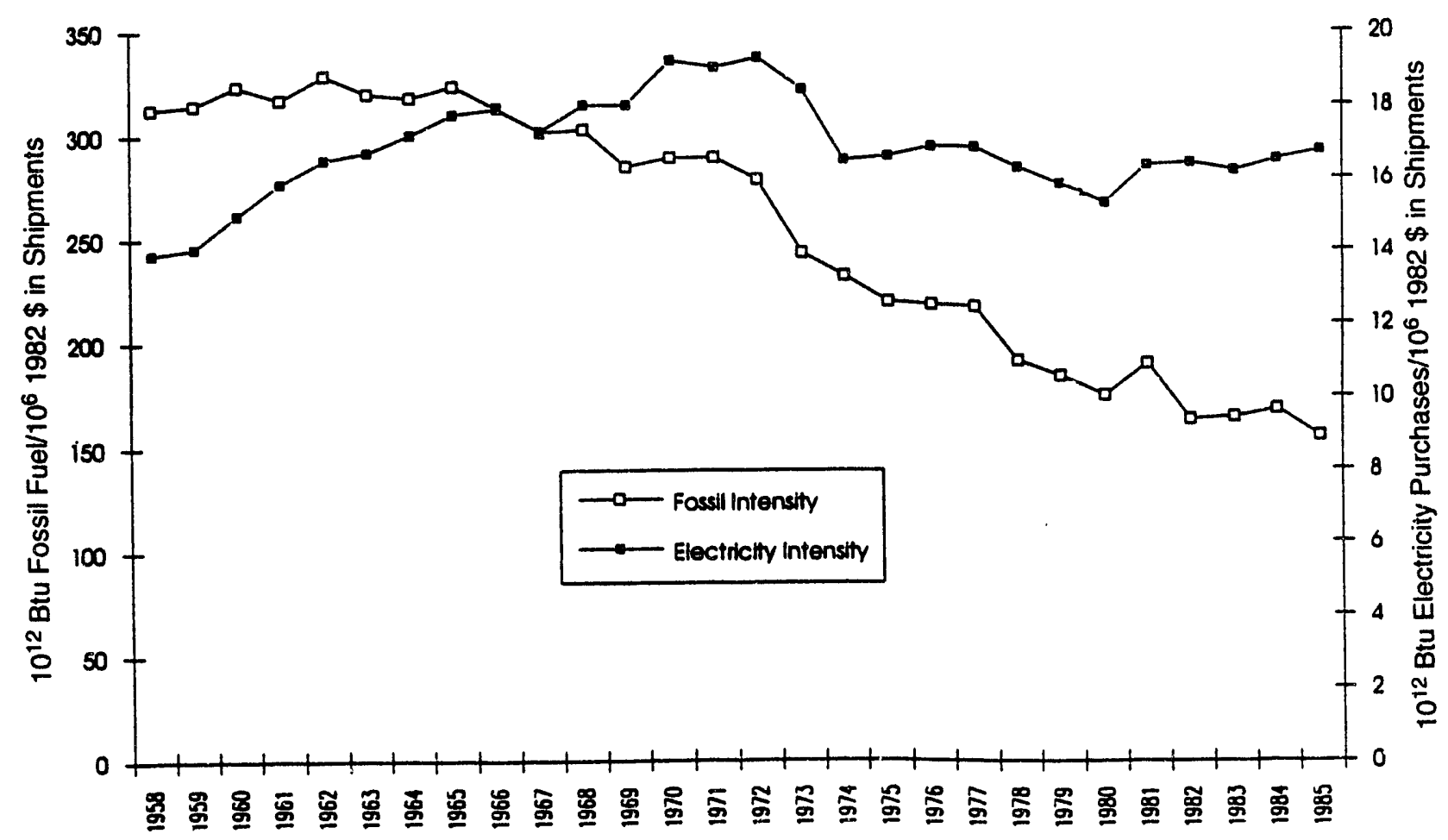

FIGURE 7 Energy Intensity in the Cement Industry (Source: NEA 1988)

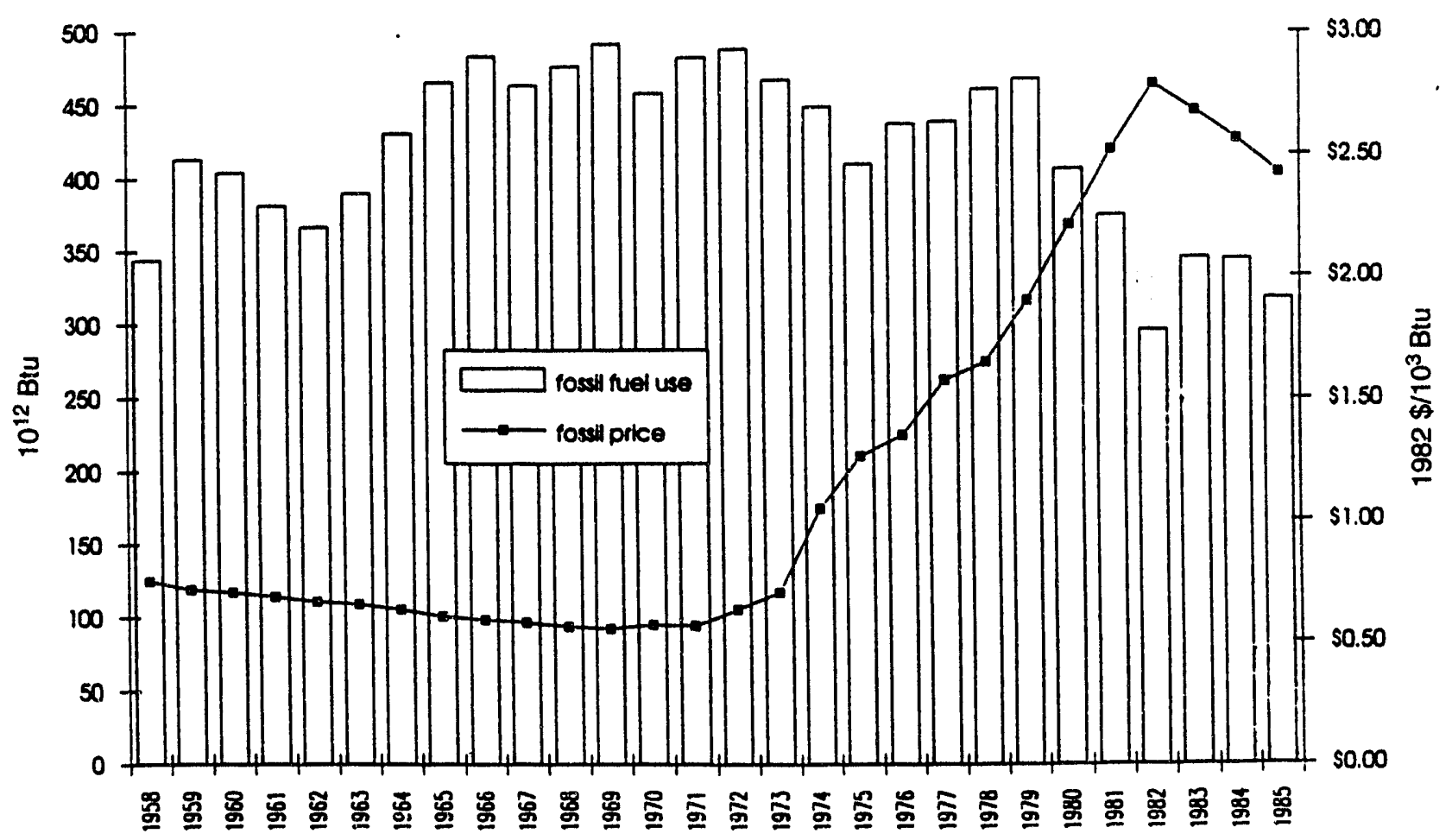

FIGURE 8 Fossil Fuel Use and Prices in the Other Stone and Clay Industry (Source: NEA 1988) 


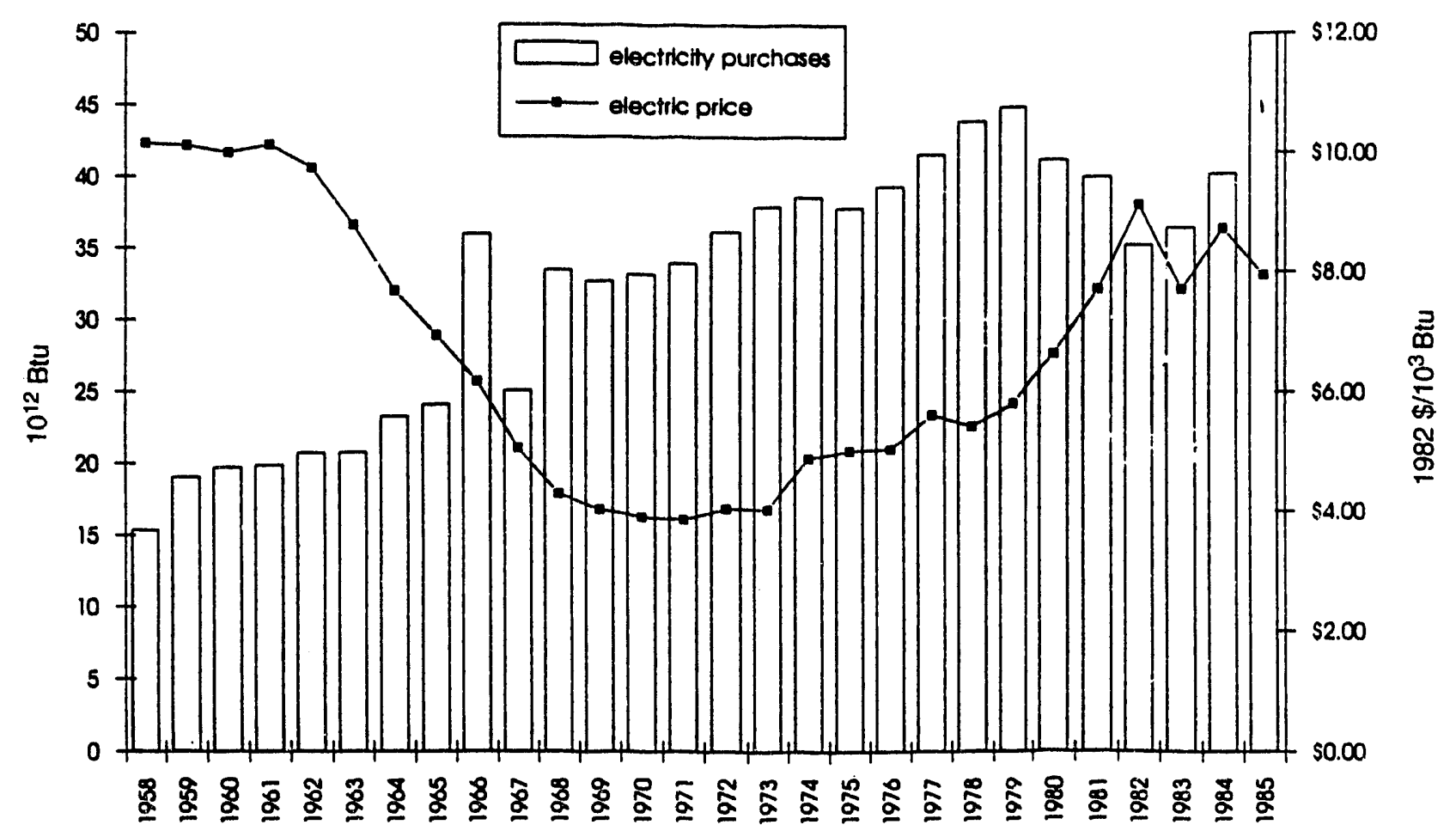

FIGURE 9 Electricity Use and Prices in the Other Stone and Clay Industry (Source: NEA 1988)

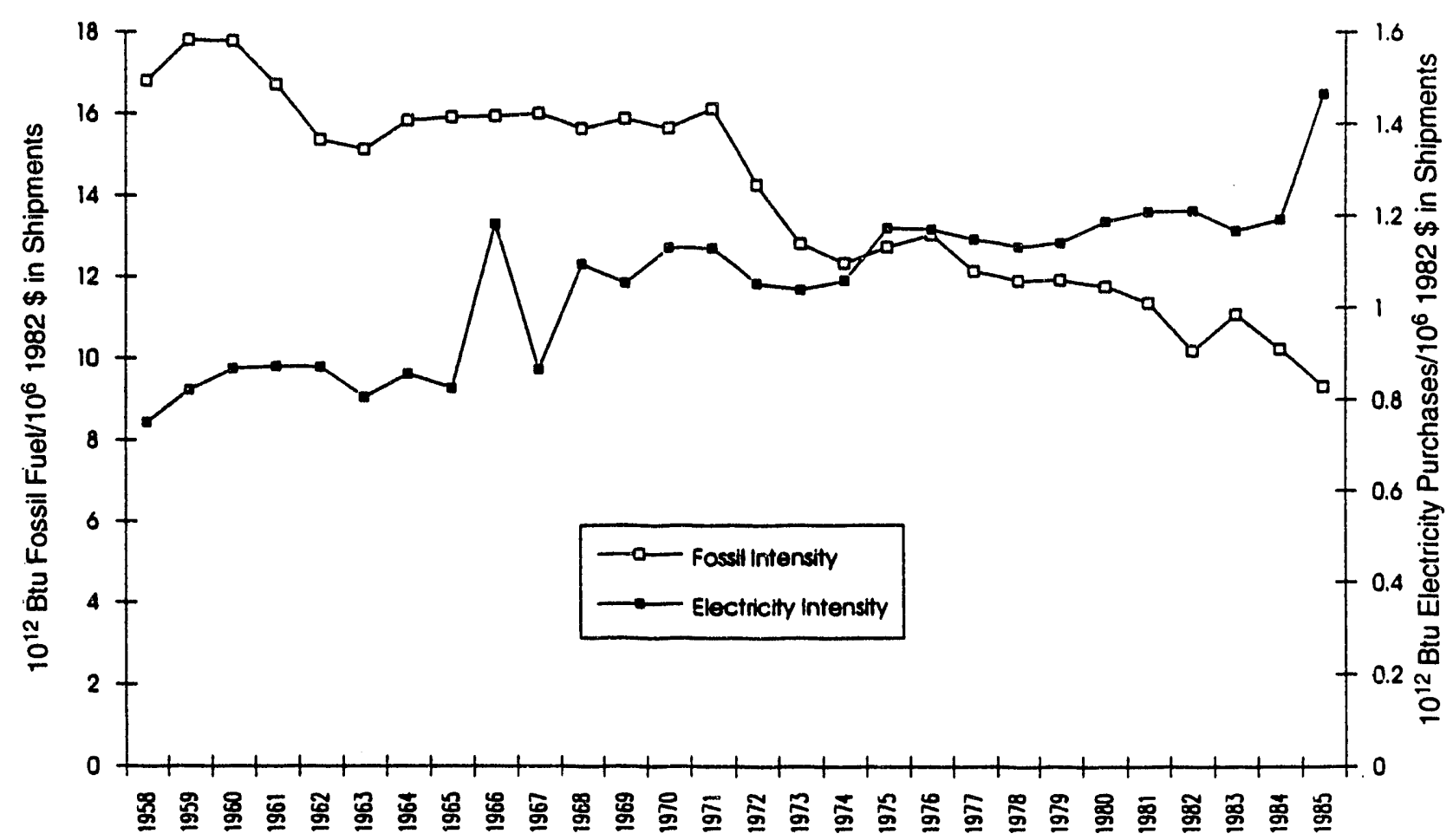

FIGURE 10 Energy Intensity in the Other Stone and Clay Industry (Source: NEA) 


\section{CONSERVATION SUPPLY CURVE ANALYSIS}

This section addresses the effect that carbon iaxes might have on energy intensity and carbon emission intensity in the glass, cement, and other stone and clay subsectors. This analysis deals with carbon emission taxes at a moderate ( $\$ 25$ per metric ton of carbon) and high ( $\$ 100$ per metric ton) level. When only the direct impacts of the $\$ 100$ tax are considered, costs would increase an average of $3 \%$ in the glass and other stone and clay subsectors and more than $40 \%$ in the cement subsector (Table 3). For the lime industry, the cost increase would be almost $50 \%$ (footnote d, Table 3 ). The analysis assumes that the domestic production and financial condition of firms in SIC 32 would be unaffected by these cost increases. For cement, this assumption is examined in Section 5.

\subsection{METHOD OF ANALYSIS}

For each subsector, three forecasts were developed by using the long-term industrial energy forecasting (LIEF) model. This model has been extensively documented elsewhere and is described only briefly here (Ross and Hwang 1992). LIEF analyzes changes in energy intensity associated with two effects:

1. Fundamental process or autonomous change, independent of energy prices, and

2. Energy-conservation and fuel-switching investments associated with changes in energy prices.

Only two energy forms are considered - aggregate fossil fuels and electricity. Switching among fossil fuels is not considered in this section. Because natural gas is already the dominant energy source used for heat and power in almost all manufacturing sectors and because it is the fuel usually chosen in response to carbon taxes, it is not a serious deficiency that switching is not considered. However, fuel switching in the cement industry does need to be examined separately, since coal is the dominant fuel in that industry. The issue is addressed in Section 4. There is explicit switching between electricity and fossil fuel in the model, which is driven by fuel price differences.

The autonomous change is a simple time trend in the energy intensity of the form $\exp [-B(1-t / b p r) t]$ involving the parameters $B_{j}$, which are different for each sector and energy form, and bpr, the time taken for the autonomous trend to go to zero. The historically determined trends are electrification $\left(B_{e}<0\right)$ and fuel efficiency improvement $\left(B_{f}>0\right)$. The magnitude of each autonomous trend declines to zero in a period (bpr is about 100 years) going beyond the end of the forecast. Switching between electricity and fossil fuel is found to be a very limited opportunity, since most such switching is driven instead by process and product considerations, represented by the parameters $B_{j}$. 
TABLE 3 Percent Cost Increase under a $\$ 100$ Carbon Tax $^{\mathbf{a}}$

\begin{tabular}{|c|c|c|c|}
\hline Industry & $\begin{array}{l}\text { From Fuel } \\
\text { Combustion }\end{array}$ & $\begin{array}{c}\text { From } \\
\text { Material } \\
\text { Processing }\end{array}$ & Total \\
\hline $\begin{array}{l}\text { Giass } \\
\text { Cemerit } \\
\text { Other stone and clay }\end{array}$ & $\begin{array}{r}2.6 \\
19.0 \\
2.2\end{array}$ & $\begin{array}{r}0.5^{b} \\
24.0^{c} \\
0.8^{d}\end{array}$ & $\begin{array}{r}3.1 \\
43.0 \\
3.0\end{array}$ \\
\hline \multicolumn{4}{|c|}{$\begin{array}{l}\text { Compared with value of shipments. Values are based on } 1990 \\
\text { Annual Survey of Manufactures (ASM) and } 1988 \text { Manufacturing } \\
\text { Energy Consumption Survey (MECS). }\end{array}$} \\
\hline \multicolumn{4}{|c|}{$\begin{array}{l}\text { Emissions of } 0.054 \mathrm{t} \text { of } \mathrm{C} \text { as } \mathrm{CO}_{2} \text { per ton of glass produced and } 1990 \\
\text { average value of } \$ 91 \text { per ton of glass. }\end{array}$} \\
\hline \multicolumn{4}{|c|}{$\begin{array}{l}\text { Emissions of } 0.143 \mathrm{t} \text { of } \mathrm{C} \text { as } \mathrm{CO}_{2} \text { per ton of cement produced and } \\
1990 \text { average value of } \$ 55 \text { per ton of cement. }\end{array}$} \\
\hline \multicolumn{4}{|c|}{$\begin{array}{l}\text { Emissions of } 0.214 \mathrm{t} \text { of } \mathrm{C} \text { as } \mathrm{CO}_{2} \text { per ton of lime produced and } 1990 \\
\text { total shipments for all other stone and clay of } \$ 42 \text { billion. On the } \\
\text { basis of lime shipments costing } \$ 720 \text { million and } 16.5 \text { million tons } \\
\text { of lime being produced, the process cost increase for lime alone is } \\
45 \% \text {. }\end{array}$} \\
\hline
\end{tabular}

The conservation investment opportunities are described by a conservation supply curve (CSC). The CSC specifies the cost-effective, or optimal, energy intensity as a function of $\mathrm{Ep}(\mathrm{t}) / \mathrm{CRF}$, where $\mathrm{Ep}(\mathrm{t})$ is the expected price of energy and CRF is the implicit, or behavioral, capital recovery factor for conservation investments by the industry (Ross and Hwang 1992). The following analysis assumes that overall financial decision making is not affected by the carbon taxes and that the implicit CRF is not varied, so it does not play a direct role. Slope parameters $A_{j}$ and $B_{j}$ and gap $0_{i j}$ (the base-year conservation opportunity) define CSC in relative terms. The slope parameter A is a long-term own-price elasticity. These parameters are determined from the historical data (Section 2.2) and vary with sector and energy form.

LIEF embodies gradual investment, which moves manufacturers from the existing toward the optimal energy intensities. This change is governed by the series pen(t), the optimal yearly rate by which that gap is closed. The parameter pen(t) is assumed to vary systematically in accordance with changes in energy prices and other major energy events like the natural gas shortage of 1970-1971. Typical penetration rate responses are deduced from historical experience (Ross and Hwang 1992). Within these constraints, different penetration sets are chosen to improve the fits to historical behavior (Table 4).

In the following two subsections, the model is fit to historical data for the three industries. Next, on the basis of the parameter sets deduced, a base-case forecast and the two carbon tax forecasts are created. 
TABLE 4 Best-Fit Parametsrs to Historical Data for the Three Industries

\begin{tabular}{|c|c|c|c|c|c|}
\hline \multirow{2}{*}{$\begin{array}{c}\text { Production } \\
\text { Series }\end{array}$} & \multicolumn{2}{|c|}{ Glass } & \multicolumn{2}{|c|}{ Cement } & \multirow{2}{*}{$\begin{array}{c}\begin{array}{c}\text { Other Stone } \\
\text { and Clay }\end{array} \\
\text { BLS } \\
\end{array}$} \\
\hline & BLS & Physical & BLS & Physical & \\
\hline Pen set ${ }^{a}$ & $\mathrm{C}$ & B & C & D & A \\
\hline$A_{0}$ & 0.20 & 0.26 & 0.29 & 0.20 & 0.20 \\
\hline $\mathrm{Gap0}_{\mathrm{e}}$ & 0.10 & 0.10 & 0.29 & 0.22 & 0.21 \\
\hline$B_{e}$ & -3.20 & -2.50 & -3.48 & -3.25 & -2.88 \\
\hline $\mathbf{R}^{2}$ & 0.94 & 0.95 & 0.98 & 0.92 & 0.87 \\
\hline$A_{f}$ & 0.20 & 0.25 & 0.20 & 0.20 & 0.20 \\
\hline $\operatorname{Gap0}_{f}$ & 0.10 & 0.10 & 0.10 & 0.24 & 0.17 \\
\hline $\mathbf{B}_{\mathrm{f}}$ & 0.70 & 1.22 & 0.5 & $0.4 v$ & 0.85 \\
\hline $\mathbf{R}^{2}$ & 0.78 & 0.98 & 0.83 & 0.94 & 0.95 \\
\hline
\end{tabular}

a Pen set $A$ : $\quad 0=1958-1970,5=1971-1973,10=1974-1978,15=1979-1982$, $10=1983,5=1984$-end of project.

Pen set B: $\quad 0=1958-1972,5=1973-1974,10=1975-1983,5=1984$-end of period.

Pen set $C: \quad 0=1958-1970,5=1971-1973,10=1974-1984,5=1984$-end of period.

Pen set D: $\quad 0=1958-1968,5=1969-1978,15=1979-1.984,10=1985$-end of period.

Sources: BLS refers to data on real gross output (U.S. Bureau of Labor Statistics).

Physical refers to data on number of glass bottles shipped (Current Industrial Report) and barrels of portland cement shipped (Survey of Current Business).

\subsection{HISTORICAL ANALYSIS}

\subsubsection{Methodology}

The application of LIEF to individual industrial sectors is examined for the glass, cement, and other stone and clay industries in SIC 32 (Table 3). Energy and energy price data from NEA and a production series on real gross output (shipments corrected for inventory change) from BLS for the period 1958-1985 (1958-1988 for cement) are used as the input data. There are some obvious data problems, evidenced by sudden changes in energy intensity and price. An alternative production series is considered for glass and cement to provide a measure of the importance of data variability. The basis for the glass series is the number of bottles shipped (from Current Industrial Report [CIR]) and, for the cement series, it is barrels of portland cement shipped (from the Survey of Current Business [SCB]). 
LIEF essentially involves an energy intensity forecast. To determine the fossil fue? and electricity intensities, base-year intensities and energy price histories are specified. Several parameters describing technological opportunities and behavior also need to be specified. The principal parameters and acceptable ranges for them, determined from previous work, are shown in Table 5 (Ross and Hwang 1992). For each industry, the parameters are varied within these ranges to minimize the root-mean-square deviation of energy intensities in the historical forecast.

\subsubsection{Results and Interpretation}

Energy intensity results are shown in Table 4 (LIEF parameters and $R^{2}$ ) and Figures 11-16 for the cement, glass, and other stone and clay industries for purchased electricity and for fossil fuel (combined Btu). All three industries show the expected basic patterns: (1) rising electricity intensity befure the early 1970 s, with a slower rise thereafter, and (2) falling fossil fuel intensity before the early 1970s, with a more rapid decline thereafter.

Figures 11-16 also show an intermediate quantity in the modeling: the optimal energy intensity, labeled IEI (most cost effective at the implicit discount rate). The optimal intensity is influenced by changes in energy prices, while the modeled intensity, in effect, "chases after it" through penetration of conservation investments. The modeled intensity approaches the optimal intensity relatively (i.e., as a ratio), except in the glass industry, winere penetration rates are assumed to be lower.

TABLE 5 LIEF Parameters Varied in Historical Forecast

\begin{tabular}{|c|c|c|}
\hline \multirow[b]{2}{*}{ Parameter } & \multicolumn{2}{|c|}{ Range } \\
\hline & $\begin{array}{l}\text { Small } \\
\text { Effect }\end{array}$ & $\begin{array}{l}\text { Large } \\
\text { Effect }\end{array}$ \\
\hline CSC slope, $A_{i j}$ (long-term own-price elasticity) ${ }^{\mathrm{a}}$ & 0.2 & 0.8 \\
\hline $\begin{array}{l}\text { CSC intercept, gap } 0_{i j} \text { (base-year conservation } \\
\text { opportunity) }\end{array}$ & 0.1 & 0.3 \\
\hline $\begin{array}{l}\text { Autonomous time trend (\%/yr in } 1960) \\
\text { Electricity, } \mathrm{B}_{\mathrm{ei}} \\
\text { Fossil fuel, } \mathrm{B}_{\mathrm{f}}\end{array}$ & $\begin{array}{r}-2.0 \\
0.5\end{array}$ & $\begin{array}{r}-3.5 \\
1.5\end{array}$ \\
\hline Penetration rate, pen $_{i}(t)(\% / y r)^{b}$ & 0 & 15 \\
\hline
\end{tabular}

a Subscript $i$ denotes the industry and $j$ the energy form.

b Several penetration rate series were considered. 


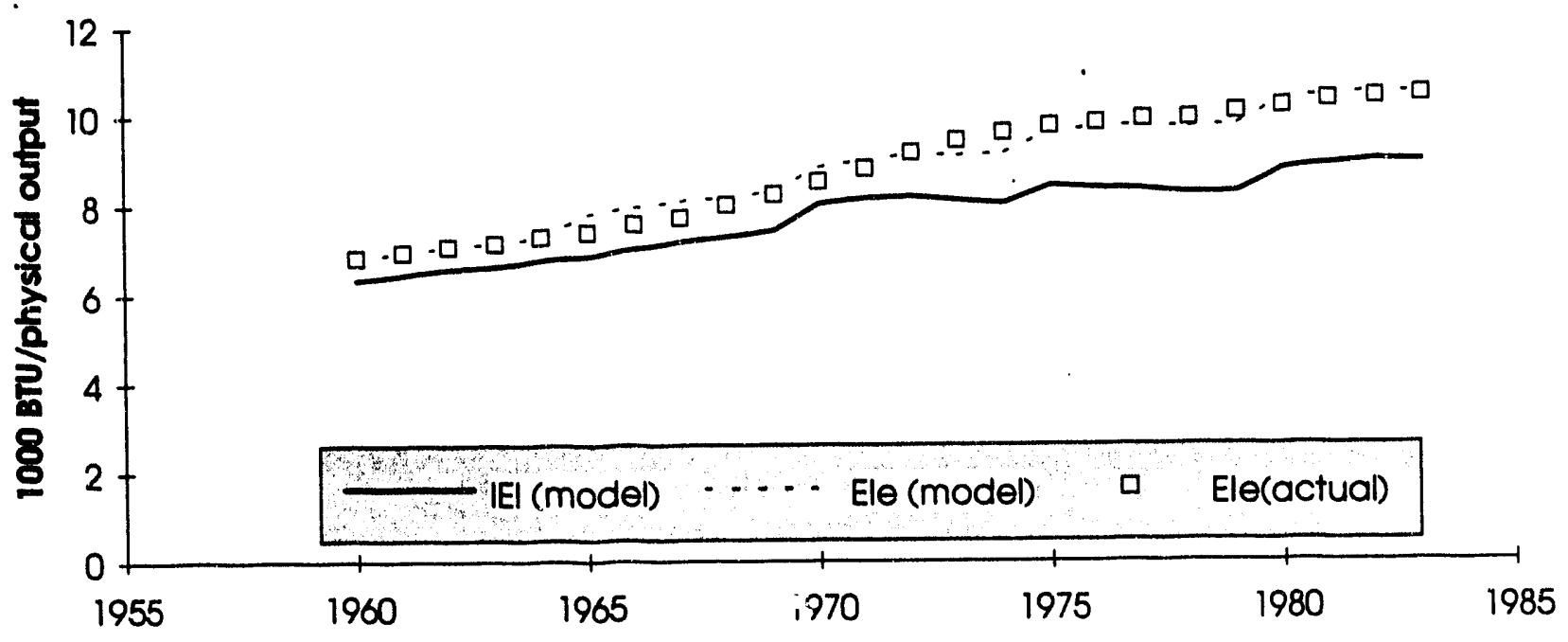

FIGURE 11 Electricity Intensity in the Glass Industry

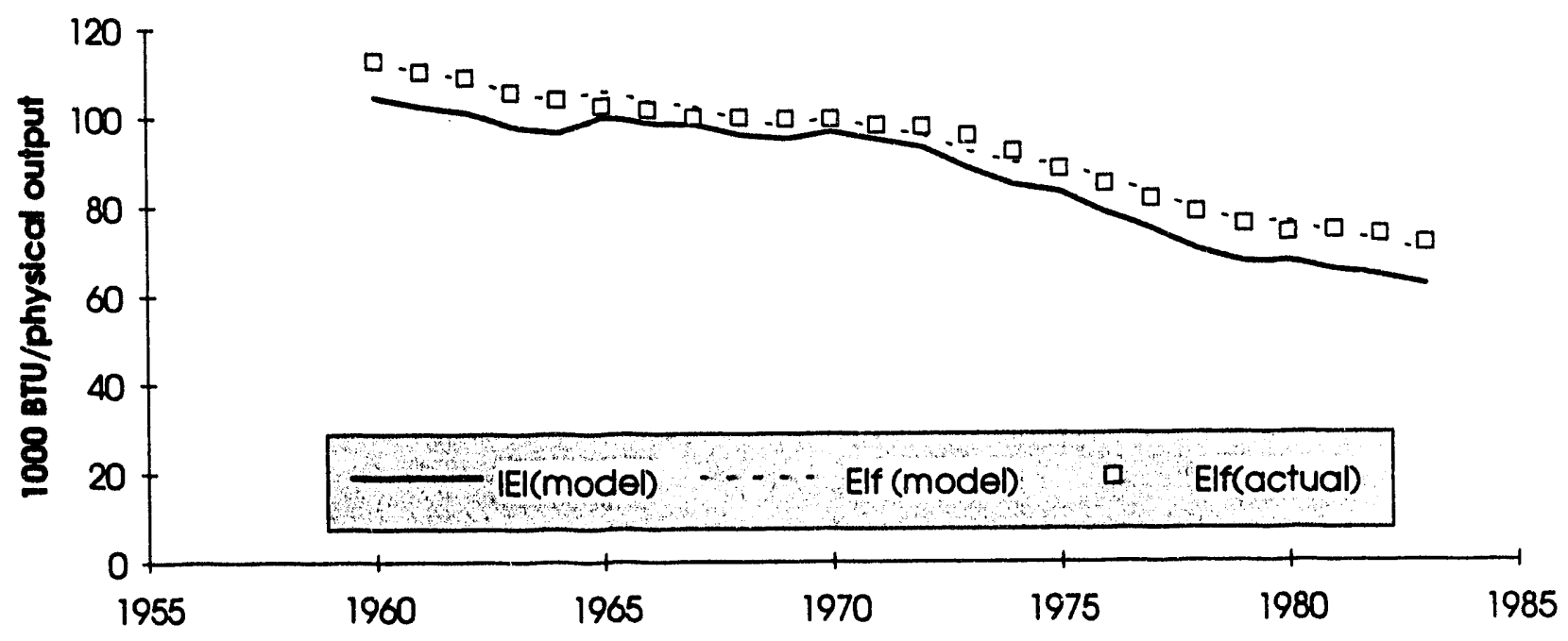

FIGURE 12 Fossil Fuel Intensity in the Glass Industry 


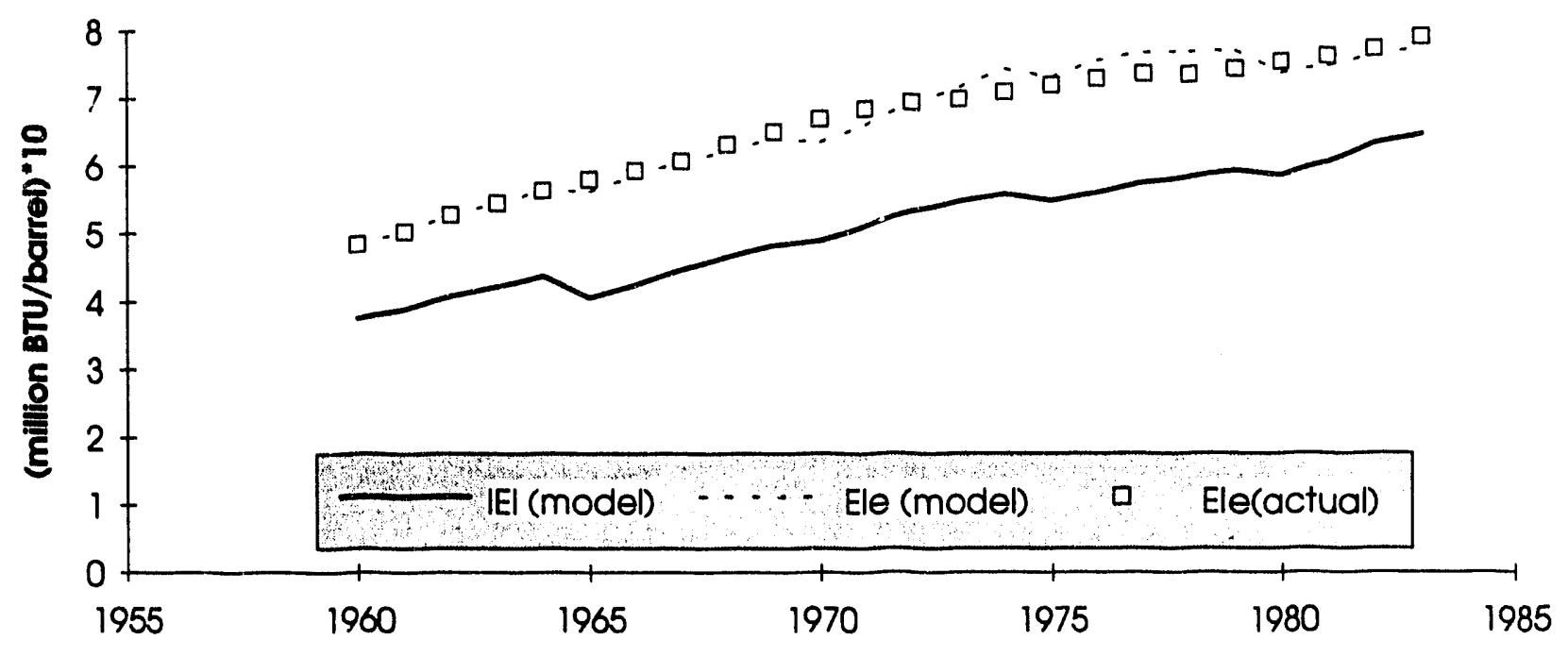

FIGURE 13 Electricity Intensity in the Cement Industry

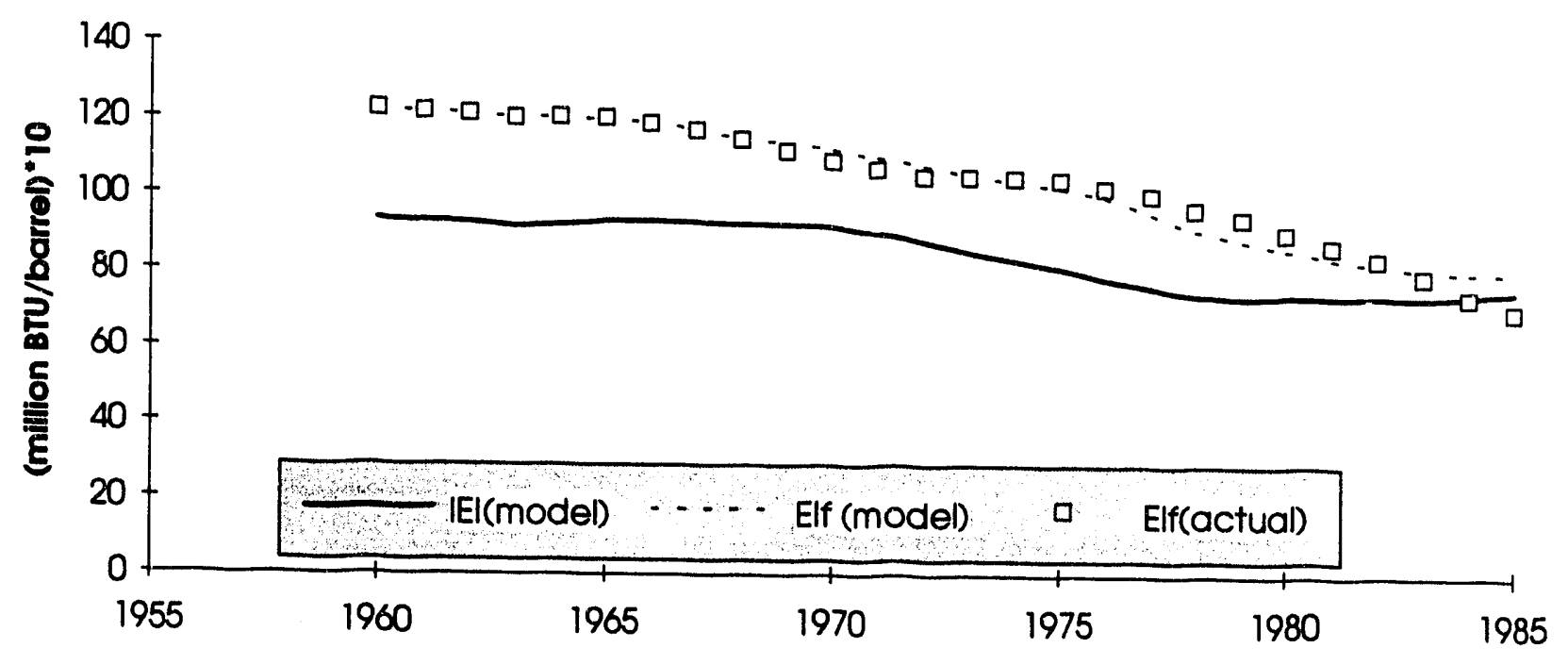

FIGURE 14 Fossil Fuel Intensity in the Cement Industry 


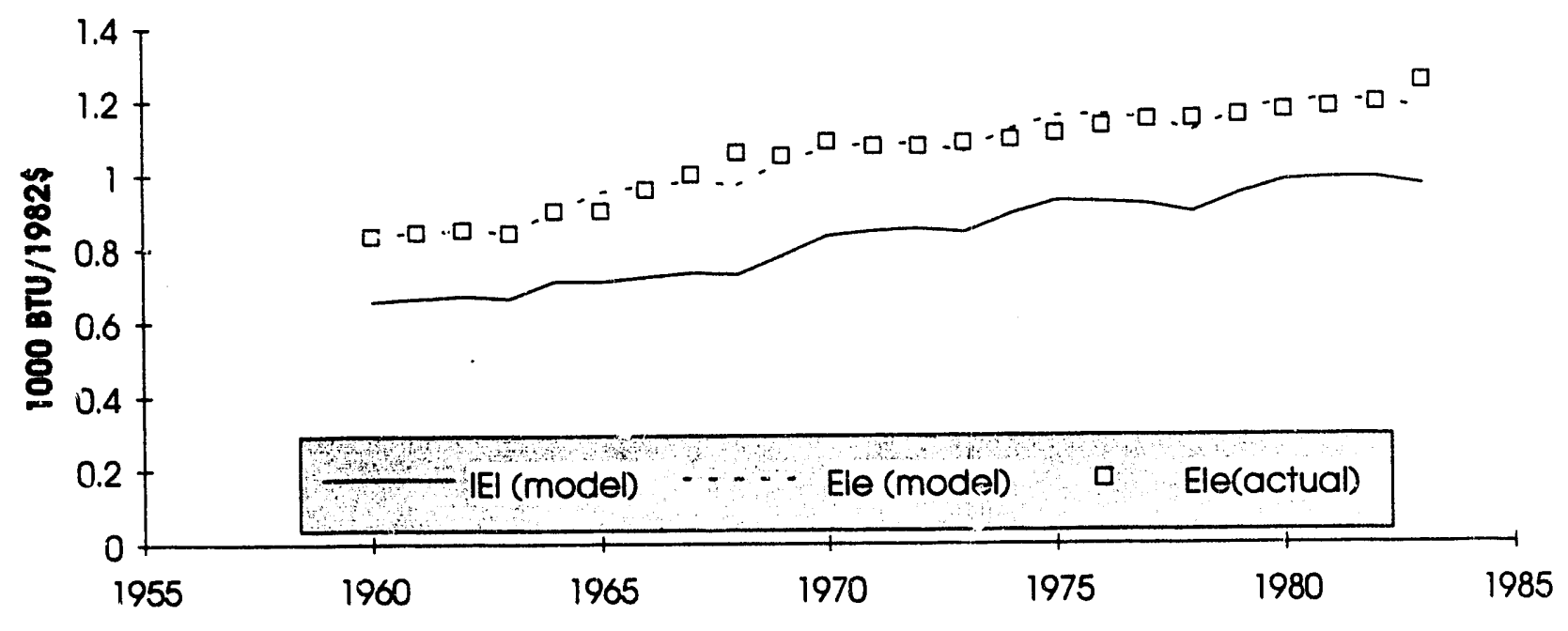

FIGUFL is Electricity Intensity in the Other Stone and Clay Industry

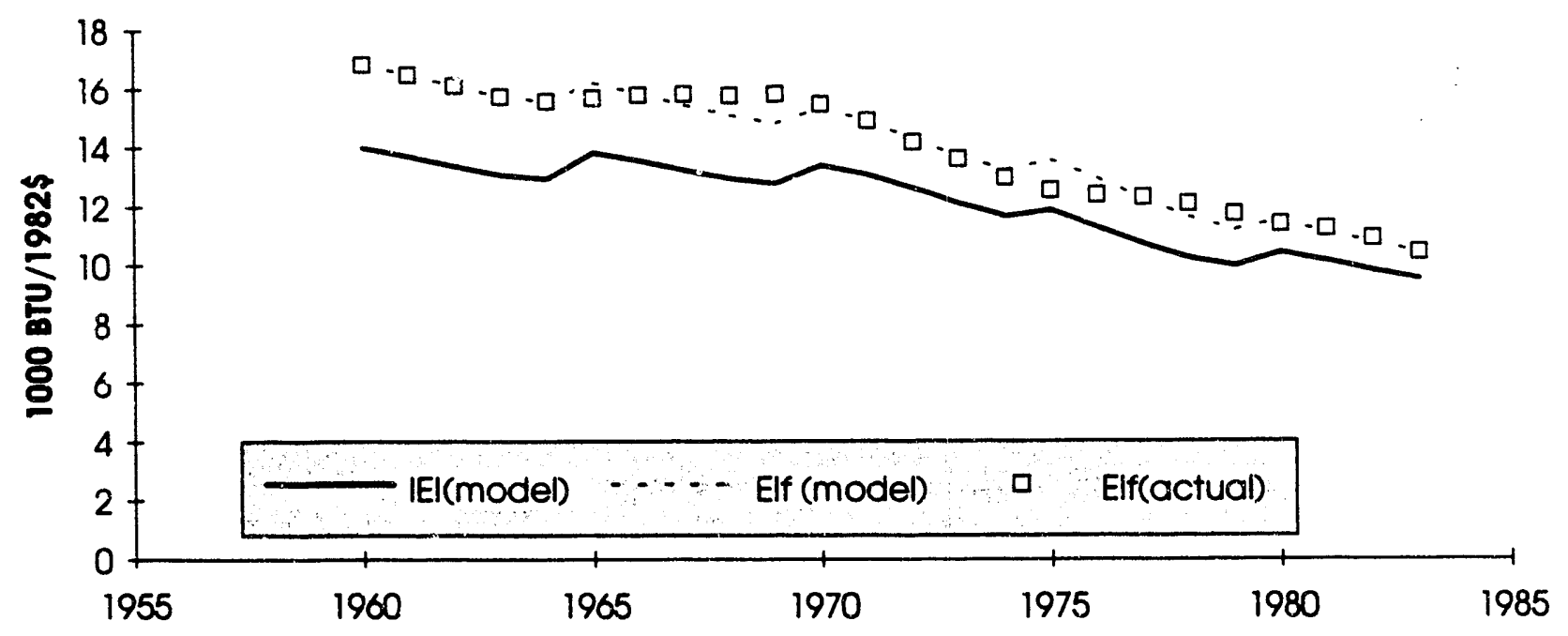

FIGURE 16 Fossil Fuel Intensity in the Other Stone and Clay Industry 
The fits are not sensitive to $A_{i j}$, although standard statistical measures cannot be determined. ${ }^{3}$ The historical forecast is substantially unaffected in most cases, with $\mathrm{A}=0.3$ instead of 0.2 , for example. One combination of the parameters $A_{j}$ and gap 0 is identified and fairly well determined; the orthogonal combination is not well identified. The $B_{i j}$ parameters are narrowly determined.

The historical behavior of the energy intensity of these three industries is found to be relatively inelastic. The relatively small values of $g a p 0_{i j}$ and of $A_{i j}$ show that there is not much opportunity for price-dependent energy-efficiency improvement and not much response to increased energy prices. In other words, the "gaps" and the magnitudes of the price elasticities are near or at the low ends of the assumed ranges. This result is not very surprising, since these are energy-intensive industries, in which the production process, both behaviorally and thermodynamically, is likely to be relatively energy efficient - given the technology available at any given time.

As can be seen, the agreement between the LIEF historical forecasts and the data is sometimes only moderately good $\left(\mathrm{R}^{2}<0.90\right)$. The essential difficulty is that in several cases, historical er,ergy intensity does not closely follow the simple pattern (an increasing trend before the early 1970s, followed by a relative decline associated with the natural gas shortages of 1970-1971 and the price shocks of 1974 and 1979). The major reason for this discrepancy is that the data series for output often deviate substantially from those for tonnage; and in these energy-intensive sectors, the mass of material processed is the critical determinant of energy intensity. There is evidence for this deviation of real gross output from tonnage. First, in the cement $i$. austry, where the product is essentially homogeneous and unchanging, tonnage $h * s$ been growing faster than BLS gross output - an average of $1.1 \%$ per year during the $p$ 'riod 1.958-1985. This condition is probably associated with data problems in constructing ine deflators. Second, actual major nonprice events within the period under study may have caused major changes in tonnage-value relationships.

The second piece of evidence can be considered in more detail. For glass, neither the gross output measure nor the physical measure (the number of bottles produced, because the glass containers subsector dominates energy consumption in the glass industry) used here is closely tied to tonnage of glass, which is the production variable closely related to energy intensity. The relationship of either production measure to tonnage would change, for example, if the mix of bottle sizes were to change. Moreover, in the late 1970s, bottles began to be made by a press and blow process, which can result in more uniform thickness (e.g., more 12-ounce beer bottles per ton of glass). In addition, beverage bottles that had been returnable were dominated by thinner varieties that could be thrown away. These changes were not timed with the shifts in energy prices.

3 The model is nonlinear and underidentified; some parameters are set on the basis of expert engineering judgment. Any statistical measures would be conditional on the assumed values of other model parameters. 
Historical energy intensity patterns may have features not readily modeled in LIEF that require energy intensity to vary smoothly unless there are major price changes. Fur example, fuel intensity in the cement industry shows (1) a pause in the intensity decline in the early 1970s and (2) a steepening decline in the mid 1980s (Figure 14). The pause might be associated with a shift from natural gas to coal and with some inertia because of the high capital intensity of this industry. The steepening decline in the $1980 \mathrm{~s}$ might be associated with foreign competition in coastal regions and the closure of small plants and their replacement with very large, modern, efficient kilns.

\subsubsection{Conclusions}

The main conclusion from fitting the CSC in LIEF to SIC 32 is that these industries exhibit relatively low energy-price elasticities, represented here by the small values of $A$ and Gap0 (Table 4). For example, if $\mathrm{A}=0.2$ and $\mathrm{Gap0}=0.1$, at existing energy prices, the long-run energy intensity would involve a savings of only about $10 \%$ when compared with current average practice. In other words, these values represent the as-yet-uritapped energy savings that meet manufacturers' implicit financial criteria. They represent energy-saving measures delayed for other than financial reasons. If energy prices were doubled, the long-run energy savings would be only about $22 \%$.

A second conclusion relates in a small way to modeling: analysis of disaggregate industries is different from analysis of aggregate industries. In aggregate analysis, data problems and technological events not explicitly accommodated for in a model are, to a degree, "smoothed over." Better fits might be achieved with aggregate data, but their meaning is likely to be less clear. More important is the fact that modeling of disaggregate sectors can be greatly improved. The issue of aggregate versus disaggregate modeling is further examined in Section 3 in a plant-level analysis of the cement sector.

\subsection{CARBON EMISSION REDUCTIONS}

The LIEF parameters obtained by fitting historical data are roughly similar for the three industries under consideration, when the lack of identification discussed above is taken into account. Moreover, in the model, the percentage reductions in electricity and fossil fuel intensities to be forecast are essentially independent of two industry-specific characteristics: production growth rate and base-year energy use (Hwang and Ross 1992). For the glass and other stone and clay industries, the fuel mix is dominated by natural gas, so the futures of fuel prices in these industries are likely to be similar. For these reasons, the first need is for an overview, obtained by forecasting with two sets of the parameters $\left(A_{e}, g a p 0_{e}\right.$ and $A_{f}$, gap $0_{\mathrm{f}}$ ), to examine the range of variation within the context of LIEF. One combination of this pair of parameters suffers from lack of identification. Parameters that are both less and more price elastic are considered, consistent with the historical data. A separate forecast is made for the cement industry on the basis of its 1988 fuel mix. 
Results on decreases in energy use relative to the base case are shown in Table 6 . The maximum reductions that are forecast are $11 \%$ for electricity use and $16 \%$ for fossil fuel use. These occur under a scenario representing a $\$ 100$ tax and CSC parameter sets that are more elastic. The reductions in fuel use are greater than the reductions in electricity use because, although the historical analysis suggests electricity use is slightly more elastic, fuel prices are predicted to increase substantially, while electricity prices are predicted not to increase substantially, even under a carbon tax. This result follows from the base-case price forecast taken from the 1991 NES. If one adopts the NES electricity forecast and the assumption that the aggressive (carbon-reduction/electricity supply mix) scenario (NES excursion) does not affect electricity prices, one finds that the $\$ 25$ tax only manages to bring the price of electricity above the 1985 base-year level. In LIEF, a carbon tax policy will cause penetration of both fuel and electricity conservation investments, but the ponetration opportunities are greater for fuel than electricity because of the relatively large price increase for fuel and the relatively small price increase for electricity.

Another characteristic of the results is saturation: the energy-demand reductions achieved under a $\$ 100$ tax are basically four times less than those achieved under a $\$ 25$ tax. Finally, these reductions are less than those that have been forecast by the same methodology for the entire manufacturing sector (Hwang and Ross 1992). For the entire

TABLE 6 Reduction in Energy Use under Carbon Taxes (percent relative to base case)

\begin{tabular}{|c|c|c|c|c|c|c|}
\hline \multirow[b]{3}{*}{ Energy } & & & \multicolumn{4}{|c|}{ Carbon Tax Scenario, by Year } \\
\hline & \multicolumn{2}{|c|}{ Parameters $^{\mathbf{a}}$} & \multicolumn{2}{|c|}{$\$ 25 / t$} & \multicolumn{2}{|c|}{$\$ 100 / t$} \\
\hline & A & gap0 & 2010 & 2030 & 2010 & 2030 \\
\hline Electricity & $\begin{array}{l}0.20 \\
0.30\end{array}$ & $\begin{array}{l}0.10 \\
0.20\end{array}$ & $\begin{array}{l}1 \\
2\end{array}$ & $\begin{array}{l}3 \\
4\end{array}$ & $\begin{array}{l}4 \\
7\end{array}$ & $\begin{array}{c}7 \\
11\end{array}$ \\
\hline $\begin{array}{l}\text { Fossil fuel } \\
\text { (average mix) }^{b}\end{array}$ & $\begin{array}{l}0.20 \\
0.30\end{array}$ & $\begin{array}{l}0.10 \\
0.10\end{array}$ & $\begin{array}{l}3 \\
4\end{array}$ & $\begin{array}{l}5 \\
7\end{array}$ & $\begin{array}{c}8 \\
11\end{array}$ & $\begin{array}{l}12 \\
16\end{array}$ \\
\hline $\begin{array}{l}\text { Fossil fuel } \\
\text { (cement mix) }\end{array}$ & 0.20 & 0.15 & 3 & 6 & 10 & 15 \\
\hline
\end{tabular}

a $\operatorname{Pen}(\mathrm{t})$ for base case: $2=1990-2010,1=2015-2030$.

Pen(t) for $\$ 25 /$ t scenario: $2=1990-2000,3=2005-2010,2=2015-2030$.

Pen(t) for $\$ 100 / t$ scenario: $2=1990-1995,3=2000,5=2005-2010,3=2015-2030$.

b For all industries. 
sector, primary energy demand by 2030 is reduced $7 \%$ under a $\$ 25$ tax and $18 \%$ under a $\$ 100$ tax. This result is expected, because energy use by the entire manufacturing sector is more elastic than use by the SIC 32 industries.

The final results in this section are carbon emission reduction estimates for the two tax levels for the separate industries. Parameters are chosen as indicated in Table 7, based on the historical fits shown in Table 4. (The reductions in carbon emissions vary slightly with the assumed parameters, especially depending on the gap parameter assumed for the fossil fuel intensities in the base year.)

The base-case carbon emissions and reductions considered here are associated with fuel use for heat and power and not with $\mathrm{CO}_{2}$ emissions from materials being processed (Table 3). The percent carbon reductions achieved (Table 7) are similar to the fossil fuel use reductions (Table 6) but slightly less. This result follows from the dominance of fuel use in SIC 32 overall (even in year 2030) and from the similarity of the carbon burdens (in kilograms of carbon per million Btu, comparing electrical energy and fuel energy).

These carbon reductions of about 5\% for the $\$ 25$ tax and $12 \%$ for the $\$ 100$ tax are smaller than those predicted in other studies (Goulder 1992) for three reasons. First, other studies deal with more aggregate sectors, including industries where conservation opportunities and elasticities are much greater. Second, this analysis describes gradual investment in conservation rather than an equilibrium situation. Even after a long period with high energy prices, significant cost-effective conservation opportunities remain unrealized. Finally, this analysis does not include shifting from coal and oil to natural gas, which is examined in Section 4. 


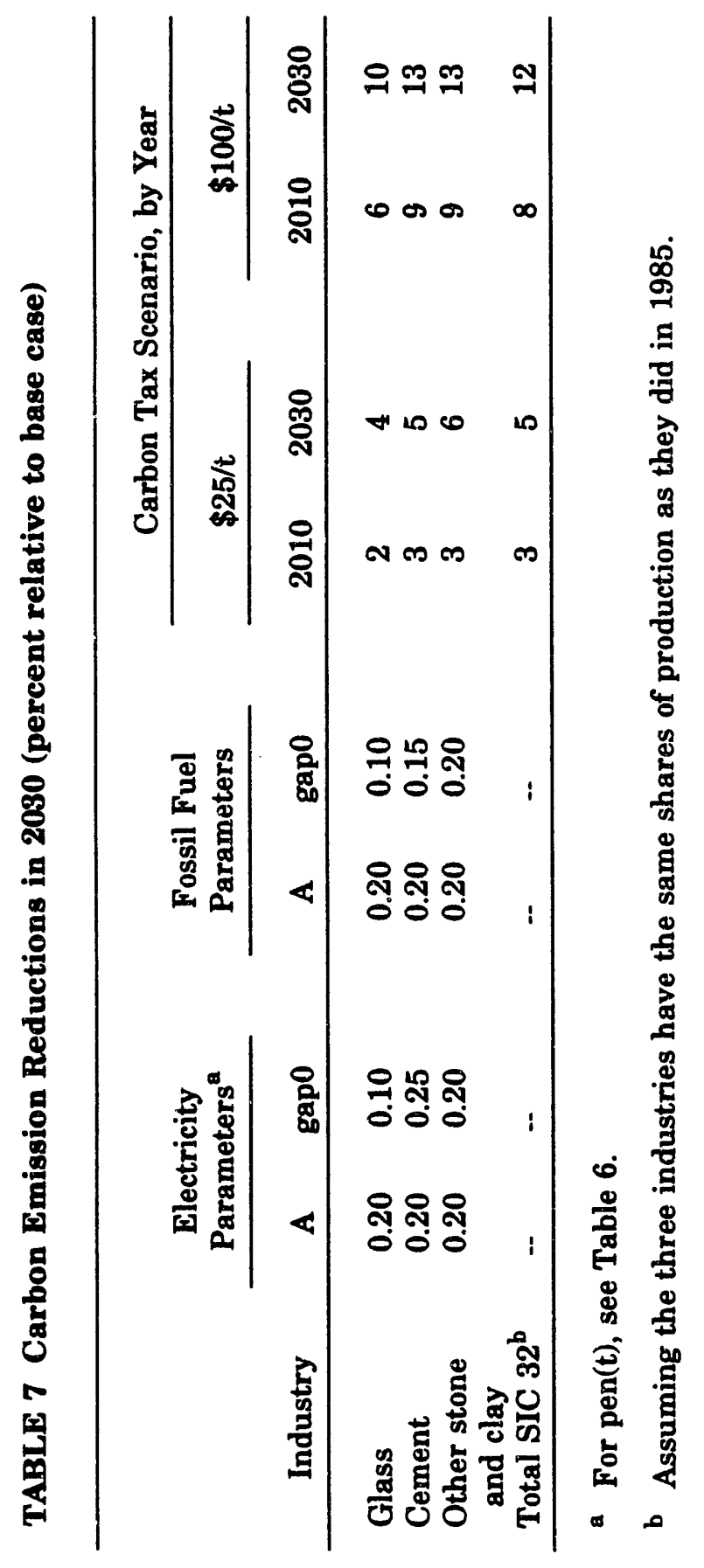




\section{PLANT-LEVEL ANALYSIS OF CEMENT MANUFACTURING}

This section approaches the question of the ability of cement manufacturers to mitigate $\mathrm{CO}_{2}$ emissions under a carbon tax. A statistical model of plant-leve! input demand is applied. Inferences can also be made about the impact of the carbon tax on variable costs and profitability in the cement industry. There are two major reasons for performing a plant-level analysis of the cement industry. The first is this industry's energy intensity. While SIC 32 overall has the fourth highest energy intensity of any two-digit sector (EIA 1991), the energy intensity for the cement segment is higher still. Because cement is a relatively low value commodity with a high energy cost share, its energy intensity is more than 10 times that of the glass and stone/clay segments of SIC 32 (see Figures 4, 7, and 10). The second reason is the homogeneity of the cement industry and its manufacturing process. This uniformity makes comparisons of plants both practical and meaningful.

The statistical model used here is based on a standard econometric approach to factor (input) demand modeling. This approach assumes the existence of a cost function that is the mathematical dual to the primal production function. The production function is a general functional specification of the productive relationship between inputs and outputs (e.g., the various amounts of capital, labor, energy, and materials that it may take to produce a ton of cement). The cost function represents the cost-minimizing input choice of the firm at a given set of input prices (see Shepard 1970). This model is based on Morrison (1988) and is similar to one applied by Boyd et al. (1991b). It treats capital as a fixed input in the short run and analyzes the problem of minimizing variable costs. To the extent that this analysis theoretically represents short-run decisions, this issue is reviewed again in Section 3.3.

\subsection{METHODOLOGY}

In this model, the variable cost function is a variant of the generalized Leontief flexible functional form with one fixed factor, capital stock $(K)$, and prices for the variable inputs: labor, electricity, fossil fuels, and materials (L,E,F,M). Constant returns to scale prevail. ${ }^{4}$ The cost function takes the form:

4 The constant returns to scale assumption is based on the notion that most plants increase capacity by adding additional kilns, which results in nominal plant-level economies of scale. Kiln-level data on production and energy use are not available, so the potential for scale economies in the kilns themselves cannot be examined. 


$$
\begin{aligned}
C= & y\left(2 \sum_{i=1}^{4} \sum_{j=1}^{4} \alpha_{l j}\left(P_{i} P_{j}\right)^{1 / 2}+\sum_{i=1}^{4} \delta_{i T} P_{i} T_{i}+\gamma_{i} t \sum_{i=1}^{4} P_{i}\right) \\
& +y^{1 / 2}\left(\sum_{i=1}^{4} \delta_{i K} P_{i} K^{1 / 2}+\gamma_{t i}(t K)^{1 / 2}\left(\sum_{i=1}^{4} P_{l}\right)\right)+\gamma_{k K} K\left(\sum_{i=1}^{4} P_{i}\right)
\end{aligned}
$$

where:

$$
i, j=L, E, F, M .
$$

ratios) by

Shepard's lemma gives the optimal variable factor demand equations (as input/output

$$
\begin{aligned}
\frac{X_{j}^{*}}{y}= & \sum_{i=1}^{4} \alpha_{i j}\left(\frac{P_{l}}{P_{j}}\right)^{1 / 2}+\delta_{j T} T_{j}+\gamma_{t} T \\
& +\delta_{j k}\left(\frac{K}{y}\right)^{1 / 2}+\gamma_{t K}\left(\frac{t K}{y}\right)^{1 / 2}+\gamma_{K K}\left(\frac{K}{y}\right)
\end{aligned}
$$

Equation 2 shows that the model predicts the input intensity (i.e., the input/output ratio) as a function of the relative prices of the inputs as well as capital inputs and time trends. The variable price coefficients are of interest in the carbon tax analysis. The capital data provide the mechanism for the long-run adjustment of variable input demands. In the usual formulation of this model, the time trends $(t)$ are a proxy for technology and technical change. This model is expanded to include a variable that indicates what major type of production technology is used in the plant - wet or dry. The above system of equations is estimated for a detailed, plant-level data set and used to compute the effect of a carbon tax on plant-level energy use, use of other input variables (i.e., materials and labor), and cost shares.

\subsection{DATA}

Data for the hydraulic cement industry (SIC 3241) were drawn from the Longitudinal Research Database (LRD) collected and maintained by the U.S. Bureau of the Census. Although the LRD contains records for 1963-1989, continuous annual data were not available until 1972. Thus, the sample chosen covers the period 1972 through 1988.

The sample period initially covered 2,455 establishments in the industry. However, the LRD data for some establishments were erroneous and were thus edited. For example, a plant needs some positive amount of labor or electricity to produce a unit of output. Thus, observations (i.e., responses) were dropped if total production hours, total production worker wages, total value of shipments, total electricity purchases, or total employment was less than or equal to zero. As a result, the sample covered 2,374 observations. The resulting number of establishments is broken down by year in column 2 of Table 8. The LRD data 


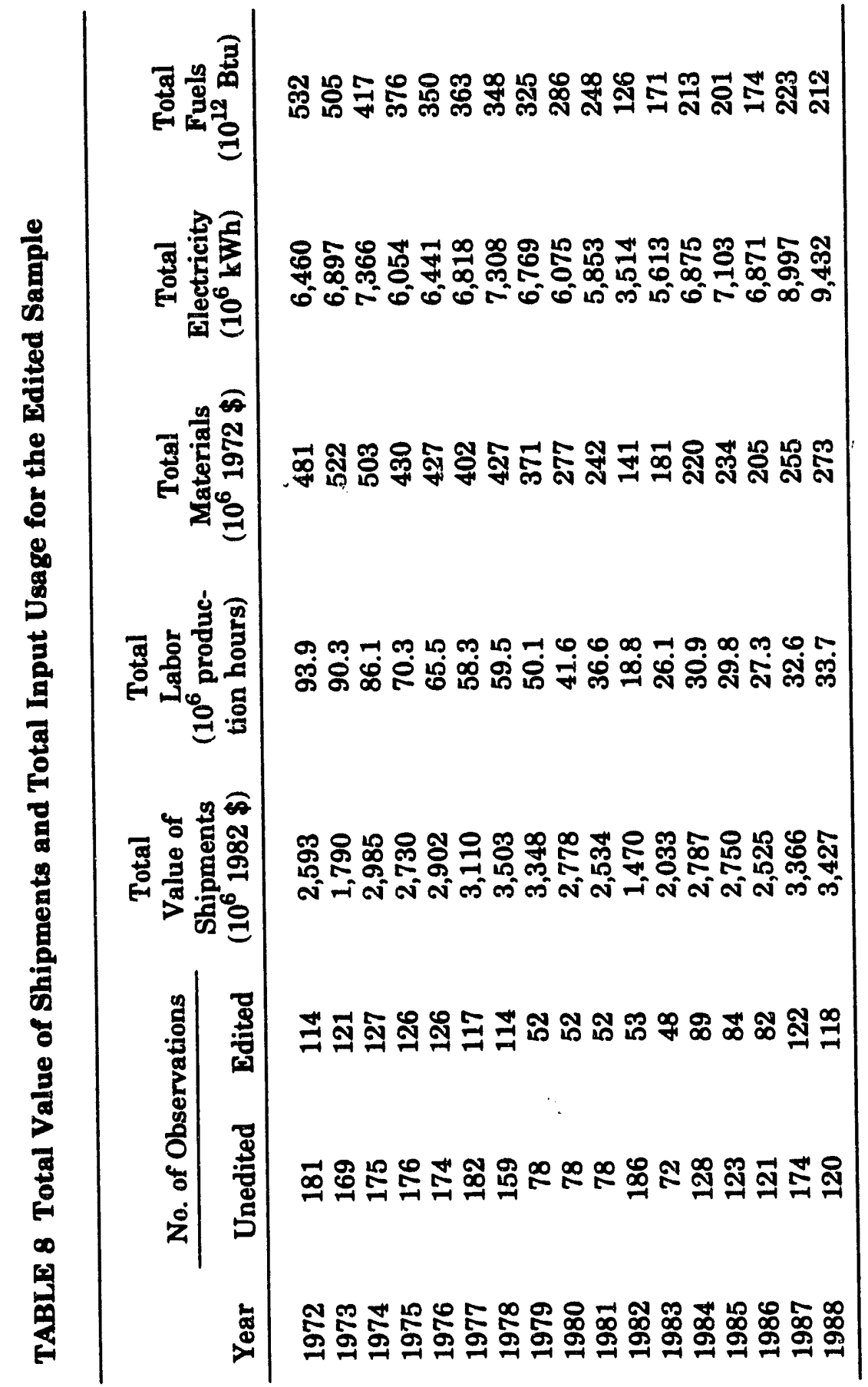


were further edited when observations were imputed. Observations are imputed when data for an establishment are missing or judged to be unreliable. Imputed observations, which are estimated from data on the entire industry, may not accurately reflect the behavior of a particular establishment. After these adjustments were made, 1,597 observations remained to be analyzed. The breakdown of these edited data by year is found in column 3 of Table 8 .

The results of the data editing are found in Table 9. Table 9 gives an idea of how representative the sample is in relationship to the total industry in terms of total shipments and total input usage. The sample is least representative for 1982, when the total value of shipments for the sample was only $42.1 \%$ of the industry total, while electricity and fuel use were $45.5 \%$ and $43.6 \%$, respectively, of total industry use. In the other 16 years, the total value of shipments for the sample ranged from $68 \%$ to $99 \%$, while electricity use ranged from $68.5 \%$ to $99.7 \%$ and fuel use ranged from $70.1 \%$ to $99.9 \%$ of total industry usage.

One drawback of the above data set is that it contains no information on the type of technology (i.e., wet or dry process) being used at each plant. Thus, to represent technology, a simple time trend would have to be used. The rationale for using this trend is that over time, new technology would lead to decreased use of inputs. In an attempt to correct this problem, a data set covering the period 1974-1990 for 425 kilns was employed. $^{5}$

TABLE 9 Edited Sample as a Proportion of Total

\begin{tabular}{|c|c|c|c|c|c|}
\hline Year & $\begin{array}{c}\text { Total } \\
\text { Value of } \\
\text { Shipments }\end{array}$ & Labor & Materials & Electricity & Fuels \\
\hline 1972 & 0.680 & 0.696 & 0.649 & 0.685 & 0.701 \\
\hline 1973 & 0.707 & 0.724 & 0.695 & 0.709 & 0.732 \\
\hline 1974 & 0.709 & 0.719 & 0.693 & 0.704 & 0.743 \\
\hline 1975 & 0.696 & 0.710 & 0.689 & 0.693 & 0.742 \\
\hline 1976 & 0.709 & 0.723 & 0.706 & 0.709 & 0.743 \\
\hline 1977 & 0.693 & 0.695 & 0.663 & 0.695 & 0.725 \\
\hline 1978 & 0.709 & 0.707 & 0.666 & 0.700 & 0.726 \\
\hline 1979 & 0.713 & 0.723 & 0.650 & 0.704 & 0.737 \\
\hline 1980 & 0.695 & 0.715 & 0.643 & 0.714 & 0.737 \\
\hline 1981 & 0.701 & 0.714 & 0.678 & 0.715 & 0.737 \\
\hline 1982 & 0.421 & 0.391 & 0.409 & 0.455 & 0.436 \\
\hline 1983 & 0.691 & 0.714 & 0.647 & 0.742 & 0.740 \\
\hline 1984 & 0.719 & 0.704 & 0.670 & 0.754 & 0.724 \\
\hline 1985 & 0.726 & 0.713 & 0.683 & 0.759 & 0.735 \\
\hline 1986 & 0.689 & 0.666 & 0.663 & 0.725 & 0.697 \\
\hline 1987 & 0.919 & 0.900 & 0.880 & 0.934 & 0.940 \\
\hline 1988 & 0.990 & 0.986 & 0.971 & 0.997 & 0.999 \\
\hline
\end{tabular}

5 This kiln-level data set had previously been compiled by D.I. Rosenbaum, an author of this report. 
It included information on the process used, capacity, type of fuel used, and the year the kiln was built. However, before these data could be used, they had to be aggregated to the plant level, since many plants use more than one kiln in production. Once aggregated, these data were matched with the LRD data. Because the names and addresses for all U.S. cement plants were not known, all the kilns could not be easily matched with firms in the LRD; only 265 of the kilns were matched. Thus, for the sample period 1974-1988, there were initially 1,470 observations: 674 used a wet process, 718 used a dry process, 43 employed both types of processes, and 35 had missing values. After the data set was edited by dropping observations with unrealistic or imputed data, 839 observations were left in the sample. The breakdown for this sample by process was 381 wet, 414 dry, 35 mixed, and 9 with missing technology data. The total value of shipments and total input usage by year are shown in Table 10. Table 11 shows how representative this sample is of the entire sample. Once again, 1982 was the least representative year. For the remaining years, total value of shipments ranged from $42.8 \%$ to $79.6 \%$. Electricity use ranged from $41.7 \%$ to $81.5 \%$, and fossil fuel use ranged from $43.6 \%$ to $85.4 \%$. This matched sample was used to estimate the model presented above and to predict the effects of both a $\$ 25$ and a $\$ 100$ tax on energy use. Despite the number of observations dropped from analysis, the sample size was more than adequate for the econometric analysis.

\subsection{RESULTS}

The model results for the energy equations are best summarized by evaluating the energy price elasticities. Energy price elasticity is the percentage change in fuel share that

TABLE 10 Total Value of Shipments and Total Input Usage for the Kiln-Level Data

\begin{tabular}{ccccccc}
\hline & $\begin{array}{c}\text { Total Value } \\
\text { No. of } \\
\text { Obs. Shipments } \\
\left(10^{6} \mathbf{1 9 8 2} \$\right)\end{array}$ & $\begin{array}{c}\text { Total Labor } \\
\left(10^{6} \text { production }\right. \\
\text { hours })\end{array}$ & $\begin{array}{c}\text { Total } \\
\text { Materials } \\
\left(10^{6} 1972 \$\right)\end{array}$ & $\begin{array}{c}\text { Total } \\
\text { Electricity } \\
\left(10^{6} \text { kWh }\right)\end{array}$ & $\begin{array}{c}\text { Total } \\
\left(10^{12} \text { Btu }\right)\end{array}$ \\
\hline & & & & & & \\
1974 & 63 & 1,891 & 50.2 & 263 & 4,583 & 259 \\
1975 & 64 & 1,791 & 42.1 & 238 & 3,928 & 246 \\
1976 & 64 & 1,900 & 39.8 & 239 & 4,245 & 237 \\
1977 & 64 & 2,136 & 37.8 & 232 & 4,633 & 251 \\
1978 & 65 & 2,377 & 37.8 & 268 & 4,934 & 236 \\
1979 & 30 & 2,071 & 29.1 & 213 & 4,010 & 192 \\
1980 & 30 & 1,711 & 24.5 & 163 & 3,605 & 185 \\
1981 & 30 & 1,642 & 23.4 & 145 & 3,605 & 162 \\
1982 & 33 & 1,132 & 14.2 & 98 & 2,641 & 98 \\
1983 & 33 & 1,540 & 19.8 & 131 & 4,202 & 139 \\
1984 & 61 & 2,038 & 23.1 & 148 & 5,207 & 162 \\
1985 & 61 & 2,121 & 23.4 & 168 & 5,511 & 157 \\
1986 & 63 & 2,143 & 22.9 & 158 & 5,726 & 144 \\
1987 & 90 & 2,701 & 25.8 & 186 & 7,199 & 177 \\
1988 & 88 & 2,757 & 26.9 & 195 & 7,710 & 181 \\
\hline
\end{tabular}


TABLE 11 Kiln-Level Data as a Proportion of Total

\begin{tabular}{cccccc}
\hline & $\begin{array}{c}\text { Total } \\
\text { Value of }\end{array}$ & & & & \\
Year & Shipments & Labor & Materials & Electricity & Fuels \\
\hline 1974 & 0.449 & 0.420 & 0.362 & 0.438 & 0.462 \\
1975 & 0.456 & 0.425 & 0.382 & 0.450 & 0.485 \\
1976 & 0.464 & 0.440 & 0.395 & 0.468 & 0.504 \\
1977 & 0.476 & 0.451 & 0.383 & 0.472 & 0.501 \\
1978 & 0.481 & 0.449 & 0.418 & 0.473 & 0.494 \\
1979 & 0.441 & 0.421 & 0.373 & 0.417 & 0.436 \\
1980 & 0.428 & 0.422 & 0.379 & 0.424 & 0.479 \\
1981 & 0.454 & 0.456 & 0.408 & 0.440 & 0.483 \\
1982 & 0.324 & 0.295 & 0.285 & 0.342 & 0.341 \\
1983 & 0.524 & 0.540 & 0.471 & 0.556 & 0.604 \\
1984 & 0.526 & 0.527 & 0.453 & 0.571 & 0.550 \\
1985 & 0.560 & 0.561 & 0.490 & 0.589 & 0.575 \\
1986 & 0.585 & 0.557 & 0.511 & 0.604 & 0.579 \\
1987 & 0.738 & 0.712 & 0.643 & 0.748 & 0.750 \\
1988 & 0.796 & 0.787 & 0.693 & 0.815 & 0.854 \\
\hline
\end{tabular}

corresponds with a $1 \%$ change in the fuel's own energy price. The elasticities are a function of the prevailing prices. An evaluation of the elasticities at the plant mean energy price in each year reveals a range of -0.53 to -0.20 for electricity and -0.69 to -0.40 for fossil fuel. This result suggests there is a modest potential for both electricity and fossil fuel conservation.

There is one major reason why this result might be biased upward as a short-run estimate. The basis for the model is the theory of short-run adjustment. However, many studies using cross-sectional, time-series data tend to interpret the results as reflecting a long-run equilibrium effect. This interpretation would be true in this case, since actual plantlevel energy prices are used, and these vary much more than do aggregate industry energy prices. For this reason, it is difficult to interpret the result entirely as a short-run estimate. In general, long-run elasticities are larger than short-run elasticities. When the long-run elasticities implied by the model are computed, they are nearly identical. However, for global climate purposes, it is the long-run adjustment that is of interest. This fact minimizes any concern about using these estimates.

Given the above caveats, simulations for a $\$ 25$ and $\$ 100$ tax were performed by using the plant-level input intensity equations. The plant-level prices observed in 1988 increased by $\$ 1.65$ ( $\$ 25$ tax) and $\$ 6.59$ ( $\$ 100$ tax) per million Btu for electricity and $\$ 0.64$ ( $\$ 25$ tax) and $\$ 2.55$ ( $\$ 100$ tax) per million Btu for fossil fuel..$^{6}$ The ratios of the predicted values of input

6 For simplicity, the fossil fuel being used was assumed to be only coal. Plant-level fuel mix data were not available; aggregate coal use in 1985 was $93 \%$ of total fossil fuel use. See Section 4 for a discussion of fuel switching. 
intensity before and after the tax were applied to each observed value for the input at the plant level. For the energy inputs, the after-tax predicted values were multiplied by the plant-level after-tax energy prices to get after-tax energy expenditures.

Table 12 shows the sample energy consumption before and after the two carbon taxes. Fossil fuel use decreased more than $32 \%$ and $52 \%$, while electricity decreased more than $10 \%$ and $13 \%$ under the two scenarios. The model indicates there is a significant nonlinearity between the amount of the tax and extent of the reductions in energy use, which suggests that initial conservation may be cost effective under relatively small carbon taxes, but larger reductions are increasingly hard to achieve.

Despite the large decrease in energy use, energy expenditures still increased. Table 13 shows the change in plant mean variable cost shares under the assumption that the plant-level value of shipments remains constant. Under the $\$ 25$ tax, energy cost shares increased $7.2 \%$ for electricity and $3.6 \%$ for fossil fuels. When the change in use of plant-level labor and materials was included, the total sample mean variable cost shares increased about $5 \%$. The $\$ 100$ tax resulted in a much larger change in the cost structure of the industry. Both electricity and fossil fuels experienced about a $35 \%$ increase in cost shares. Labor costs, which increase in response to a larger effort for additional conservation, also increased significantly. Overall, the total variable cost shares increased more than $26 \%$.

When these results are analyzed from the perspective of industry profitability, they show the industry would not be severely impacted by a $\$ 25$ tax. In 1985 , under no carbon tax, the industry averaged a $35 \%$ payment to capital ${ }^{7}$ (i.e., $35 \%$ of the value of shipments was attributable to variable costs and could go toward fixed capital costs). Under a $\$ 25$ tax, the industry's variable costs would increase to only $68 \%$ of the value of shipments, which would still leave a $32 \%$ payment to capital and very little change in profitability. However, under a $\$ 100$ tax, the share of output represented by variable costs would increase to $81.5 \%$, which would reduce payments to capital by $45 \%$ (nearly half). This higher tax would have a much more significant impact on profitability.

The preceding discussion does not cover the impact of the carbon tax on cement prices and demand. This effect would change the profitability picture, presumably by increasing cement prices and value of shipments. However, demand might also fall, so marginal suppliers would be forced out of business. The impact of supply and demand in the cement industry is discussed in Section 5.

7 Payment to capital is not the same as a rate of return. The payment to capital would need to be divided by the value of the capital stock. Because of the difficulties in valuing capital stock, a rate of return is not calculated. The issue here is not the absolute level of profitability, but how much it changes. 
TABLE 12 Predicted Plant Mean Energy Input Use before and after Carbon Taxes

\begin{tabular}{lcc}
\hline \multicolumn{1}{c}{ Parameter } & $\begin{array}{c}\text { Electricity } \\
\left(10^{6} \mathrm{kWh}\right)\end{array}$ & $\begin{array}{c}\text { Fuels } \\
\left(10^{12} \mathrm{Btu}\right)\end{array}$ \\
\hline 1988 base & $\mathbf{8 , 4 4 8}$ & 223 \\
\$25 tax & 7,572 & 151 \\
\% change from base & -10.7 & -32.4 \\
\$100 tax & 7,346 & 107 \\
\% change from base & -13.3 & -52.2 \\
\hline
\end{tabular}

TABLE 13 Predicted Plant Mean Variable Input Cost Shares before and after Carbon Taxes (\%)

\begin{tabular}{lrccrr}
\hline \multicolumn{1}{c}{ Parameter } & Labor & Materials & Electricity & Fuels & Total \\
\hline 1988 base & 15.0 & 24.2 & 12.5 & 12.8 & 64.5 \\
\$25 tax & 17.2 & 23.7 & 13.4 & 13.3 & 67.6 \\
\% change from base & +15.0 & -2.1 & +7.2 & +3.6 & +4.8 \\
\$100 tax & 21.3 & 25.8 & 16.9 & 17.4 & 81.5 \\
\% change from base & +42.5 & +6.8 & +34.8 & +35.6 & +26.3 \\
\hline
\end{tabular}




\section{ANALYSIS OF FUEL SHARES AND CARBON LOADING IN CEMENT MANUFACTURING}

The preceding sections considered the potential for conservation of electricity and fossil fuels under a carbon tax. They did not fully account for the impact of a carbon tax on the different types of fuel that make up total fossil fuel use. Because of the differing carbon content of fuels, a carbon tax falls more heavily on coal than it does on oil or gas. An objective is to examine the potential of interfuel substitution - in particular, the potential of switching from coal to natural gas - as a method of reducing carbon emissions. Substituting gas (which has lower carbon emissions) for coal would be encouraged by a carbon tax, since the tax would raise the per-Btu price of coal more than that of fuels with lower carbon contents. The estent to which a carbon tax lowers $\mathrm{CO}_{2}$ emissions through interfuel substitution depenas on the overall magnitude of coal use and the ease with which one fuel can be substituted for another.

The magnitude of coal use in SIC 32 varies significantly among the three major subsectors. The fuel shares in 1985 for each subsector are shown in Table 14. Coal use dominates the cement industry, while natural gas use dowinates the glass industry and, to a lesser extent, other stone and clay products. The heavy use of gas in the glass industry is not surprising, since glass making requires a very clean burning fuel. Since tie potential for fuel switching as a method of reducing total carbon taxes paid is greatest in the cement industry, the analysis concentrates on this sector.

Coal has not always dominated cemeat production as a fuel source. In the early 1970 s, coal accounted for only $40 \%$ of fossil fuel use, and natural gas accounted for about 50\%. The decrease in natural gas use could have resulted from three major avenues: (1) addition of new coal-using kilns, (2) early retirement or replacement of gas-using kilns, and (3) substitution of coal for gas in existing facilities. It may be that new facilities were built for coal and not gas. However, total capacity growth averaged only $1.8 \%$ per year from 1972 through 1983 . It is unlikely that this level of growth would explain all of the reduction in gas use. Das (1992) reports that 6-7\% of the kilns in her data set were retired in the 1974-1977 period. A higher amount, $18 \%$, were retired during the recessions in 1978-1980. These two effects combined could clearly have contributed to the decrease in gas use. However, these effects probably do not explain a drop from $40 \%$ to only $5 \%$.

TABLE 141985 Btu Fuel Shares for the Three Industries

\begin{tabular}{llll}
\hline Sector & Coal & $\begin{array}{c}\text { Natural } \\
\text { Gas }\end{array}$ & Oil $^{\mathrm{a}}$ \\
\hline Cement & 0.93 & 0.05 & 0.02 \\
Glass & $\mathrm{b}$ & 0.96 & 0.04 \\
Other & 0.22 & 0.65 & 0.13 \\
\hline
\end{tabular}

a Primarily residual oil, but shares shown include all other fuels as well.

b Less than $1 \%$

Source: NEA (1988) 
According to EIA (1988) estimates, slightly less than half the coal use in 1985 was switchable to gas use.

Because the reduction in gas use and increase in coal use were coincident with the energy price shocks of the mid 1970s, they probably reflected the ability of the industry to adjust its fuel mix. Thus, the short-run and long-run vehicles for the substitution of coal for gas are not separated in this analysis; instead, the industry's behavior toward energy prices and fuel choice is estimated. To make this estimate, an econometric model was used to estimate the amount of price-responsive fuel switching observed historically in the cement industry. These equations were then used to calculate the amount of fuel switching that is likely to occur under a carbon tax.

\subsection{METHODOLOGY}

The economic model used is based on the assumption that inputs of capital, labor, materials, electricity, and fossil fuel are based on their relative prices. The model then chooses to satisfy total fuel requirements. This decision process consists of two stages. The methodology for each stage could follow any particular formalism; however, one that is consistent with the plant-level analysis presented above as well as the approach used by Boyd et al. (1991a,b) was chosen. This methodology assumes the fossil fuel choice follows a generalized Leontief (GL) cost function. The underlying theory is not discussed here. ${ }^{8}$ The GL approach generates a system of equations that predict the $\mathrm{i}^{\text {th }}$ share of fossil fuel use, $F_{i} / F_{T}$, as a function of the relative prices of each fuel type. The form of the equations is:

$$
\frac{f_{i}}{F}=\beta_{i i}+\sum_{j \neq i}^{n} \beta_{i j} \times\left(\frac{P_{j}}{P_{i}}\right)^{0.5}+\tau_{i} T+\gamma Z
$$

where:

$$
\begin{aligned}
\mathrm{f}_{\mathrm{i}} & =\mathrm{i}^{\text {th }} \text { fuel, } \\
\mathrm{i} & =\text { three fuels: c, o, and } \mathrm{g} \text { (coal, oil, and gas), } \\
\mathrm{F} & =\text { total fossil fuel use, } \\
\mathrm{P}_{\mathrm{i}} & =\text { fuel prices, } \\
\mathrm{T} & =\text { some time or technology trend, }
\end{aligned}
$$

8 The approach is similar to that presented in Section 3, except that the industry cost function is replaced by an industry fossil fuel expenditure function. 


$$
\begin{aligned}
\mathrm{Z} & =\text { nonprice impacts on fuel choice, and } \\
\beta_{\mathrm{ij}}, \tau_{\mathrm{i}}, \gamma_{\mathrm{i}} & =\text { parameters that are estimated. }
\end{aligned}
$$

An equation for each fuel type (coal, oil, and natural gas) is estimated for the cement industry. Annual data for $f_{i}$ and $P i$ were taken from NEA (1988). The variable $T$ is based on an (approximate) exponential time trend. ${ }^{9}$ The variable $\mathrm{Z}$ includes any nonprice impacts on fuel choice. Over the period examined, the gas industry was deregulated. From 1974 to 1980, gas delivery was curtailed to some industrial customers. To account for the possible lack of gas availability, an index of gas curtailments (Considine 1989) is used for Z.

\subsection{STATISTICAL RESULTS}

The fuel share equations are presented in Table 15. The estimates of $\gamma_{i}$ are consistent with expectations. Curtailments increase coal and oil shares and decrease gas shares. The $\tau_{\mathrm{i}}$ estimates show small, nonprice-induced trends in fuel shares on the order of $\pm 0.5 \%$ per year. It is oil that shows an increasing trend, while coal and gas show decreasing trends. These parameters are not statistically significant for oil or gas, so no specific bias in the industry to use these fuels in preference to others is inferred. The small size and statistical insignificance of the nonprice (trend) coefficients suggest that prices are the driving force for choosing a fuel in this industry.

To better understand the price parameters $\left(\beta_{i j}\right)$, the price effect can be summarized in the form of a price elasticity. An evaluation of fuel-share price elasticities, at 1985 prices, reveals that the coal share elasticity is -0.58 , the oil share elasticity is -2.63 , and the gas share elasticity is -3.11 . These estimates indicate that the potential for fuel substitution is large.
TABLE 15 Parameter Estimates for Fuel Share Equations

\begin{tabular}{ccc}
\hline Parameter & Estimate & t-Statistic \\
\hline$\beta_{\mathrm{cc}}$ & -0.049 & -1.65 \\
$\beta_{\mathrm{co}}$ & 0.158 & 6.38 \\
$\beta_{\mathrm{cg}}$ & 0.459 & 17.54 \\
$\gamma_{\mathrm{c}}$ & 0.228 & 4.40 \\
$\tau_{\mathrm{c}}$ & -0.006 & -2.50 \\
$\beta_{\mathrm{oo}}$ & -0.083 & -3.01 \\
$\beta_{\mathrm{og}}$ & $0.032^{\mathrm{a}}$ & 1.06 \\
$\gamma_{\mathrm{g}}$ & 0.115 & 3.83 \\
$\tau_{\mathrm{g}}$ & $0.006^{\mathrm{a}}$ & 0.53 \\
$\beta_{\mathrm{gg}}$ & -0.197 & -3.43 \\
$\gamma_{\mathrm{g}}$ & -0.326 & -5.30 \\
$\tau_{\mathrm{g}}$ & $-0.004^{\mathrm{a}}$ & -1.32 \\
\hline
\end{tabular}

a Not significant at the $10 \%$ confidence level.

9 See Boyd et al. (1991b) or Walfridson (1987) for more details. 


\subsection{EFFECT OF CARBON TAX ON AVERAGE CARBON CONTENT OF FOSSIL FUEL}

Applying the $\$ 100$ tax to the average carbon contents of coal, oil, and gas yields three different tax rates to add per thousand Btu of fuel used. They are $\$ 2.55, \$ 2.10$, and $\$ 1.45$ for coal, oil, and gas, respectively. Adding these taxes to the 1985 energy prices used to obtain the above fuel share estimates yields new predicted fossil fuel shares. In 1985, the coal share was $93 \%$. A $\$ 25$ tax would lower the coal share to $79 \%$. Under a $\$ 100$ tax, the coal share would decrease to $65 \%$. The gas share would gain the most, increasing from $5 \%$ to $19 \%$ under a $\$ 25$ tax and to $29 \%$ under a $\$ 100$ tax. The oil share would increase from $2 \%$ to $3 \%$ under a $\$ 25$ tax and to $6 \%$ under a $\$ 100$ tax.

On the basis of historical fuel shares, the carbon content of fossil fuel used in cement manufacturing averaged 24.8 kilograms per thousand Btu, about that of coal. Under a $\$ 100$ tax, the change in fuel mix would lower the average carbon content to 22 kilograms per thousand Btu. This tax would reduce carbon emissions by $11 \%$ as a result of interfuel substitution. 


\section{ANALYSIS OF SUPPLY AND DEMAND IN CEMENT MANUFACTURING}

This section examines the impact of a carbon tax on the U.S. portland cement industry. Cement producers make heavy use of fossil fuels and emit significant amounts of carbon. Hence, the industry is likely to be greatly affected by a carbon tax. The analysis shows that under a $\$ 100$ tax, prices may rise one-third and production decline $17 \%$.

To examine the impact of a carbon tax on the cement industry, the model estimates industry supply and demand equations and then estimates the effects of a $\$ 25$ and $\$ 100$ tax on input prices and production costs. The model estimates these impacts so the force a carbon tax might have on cement prices and shipments can be determined.

Section 5 is organized as follows. Section 5.1 contains a discussion of the cement industry and specifies the demand and supply equations. Section 5.2 describes the data used in the analysis. Supply and demand equation results are presented in Section 5.3. In Section 5.4, the impact that a carbon tax would have on the cement industry is analyzed on the basis of previously estimated parameters. Section 5.5 is the conclusion.

\subsection{MODEL}

Portland cement is a homogeneous producer good used predominately in construction. In the period 1978-1982, less than 5\% of portland cement went toward nonconstruction activities (Exhibit 25 in PCA 1984). Given its low ratio of value to weight, portland cement is shipped only short distances. In $1977,82.5 \%$ of all shipments were within a radius of 200 miles, and $99.8 \%$ were within less than 500 miles. ${ }^{10}$ Consequently, the U.S. market for portland cement can be divided into a number of independent regional submarkets.

The production of portland cement is relatively straightforward. ${ }^{11}$ Calcium carbonate rock is crushed and then combined with lime and sand for grinding. Once ground, this raw material (known as feedstock) is fed into a kiln, where intense heat causes chemical changes in its composition. Kiln output, known as clinker, is then combined with gypsum and ground again. The end result is portland cement.

There are three general types of kiln technologies: wet feed kilns that mix the feedstock with water before it enters the kiln; dry feed kilns that use a feedstock not mixed with water; and dry preheat or precalciner kilns that preheat the feedstock. Wet feed kilns are the least energy efficient. Preheat kilns are the most energy efficient. Kiln scale economies are also important: larger kilns have lower per-unit costs than smaller kilns.

${ }^{10}$ U.S. Bureau of the Census (1977). Note that shipment figures are consistent across census years.

11 For a good description of portland cement production, see PCA (1984). 
There are essentially five variable inputs in cement production: labor, fuel (predominantly coal or natural gas) used to heat the kiln, electricity used to operate related auxiliary equipment, feedstocks, and maintenance (Das 1992). Furthermore, as variable inputs are not readily substitutable, kilns tend to exhibit near-fixed-factor production functions. Marginal costs do vary across kilns, however, on the basis of respective technologies, capacities, and ages.

A model was developed to examine the determination of equilibrium price and quantity in 25 regional cement markets over a 13-year period. A quantity equation was specified as a function of price, economic activity, and the price of substitution. A price equation was specified as a function of input costs, technology, capacity, and market concentration. The two equations were solved simultaneously to obtain parameter estimates.

\subsubsection{Quantity Equation}

The quantity equation reflects the demand side of the market. Almost all cement is used in construction activity (PCA 1984). Hence, an equation was developed to specify the quantity of cement demanded in market $i$ in period $t\left(Q_{i t}{ }^{D}\right)$ as a function of the price in market $i$ in period $t\left(P_{i t}\right)$ and three measures of construction activity: residential construction expenditures $\left(\operatorname{RES}_{\mathrm{it}}\right)$, nonresidential construction expenditures $\left(\mathrm{NRES}_{\mathrm{it}}\right)$, and highway construction expenditures $\left(\mathrm{HWY}_{\mathrm{it}}\right)$. These three categories make up approximately $80 \%$ of the demand for portland cement. ${ }^{12}$ Also included as a measure of demand was aggregate personal income $\left(\mathrm{INC}_{\mathrm{it}}\right)$. This measure should be positively correlated with the demand for cement.

Portland cement has few substitutes. In street paving, however, asphalt is an alternative. ${ }^{13}$ The price of asphalt $\left(\mathrm{PASPH}_{\mathrm{it}}\right)$ was included in the analysis and should have a positive effect on demand.

Assuming constant elasticities, demand was specified as:

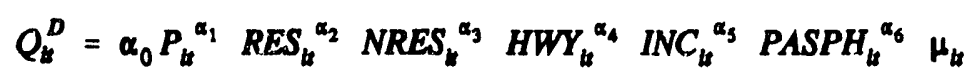

12 Ascertained for PCA data.

${ }^{13}$ In discussions, road engineers suggested that the overall costs of a project in terms of initial construction and maintenance are evaluated on the basis of the assumption that either concrete (a product made from portland cement, water, and aggregate) or asphalt is used. In cases in which other factors make substitution possible, the cheaper alternative is selected. 


\subsubsection{Price Equation}

The price equation reflects the supply side of the market. Each regional market is composed of several individual kilns. Given the nature of the production function, for any level of market input prices, the most efficient kiln will produce first. It will produce at constant marginal cost to its capacity. This fact is reflected in Figure 17. Then the next most efficient kiln will produce; however, for the same given vector of input prices, this relatively less efficient kiln will have to operate at a higher unit cost. ${ }^{14}$ This fact is indicated by the jump in the supply curve in Figure 17. The supply curve will continue to be a step function, with additional kilns coming on line at higher and higher costs. Finally, once all capacity is used, the supply curve will become vertical.

While an individual kiln's supply curve may be flat, the market supply curve will slope upward. Furthermore, for any given level of market output, the market price will depend on input prices and the relative mix of kiln technologies, sizes, and ages. Hence, the price in market $i$ at time $t\left(P_{i t}\right)$ will depend on quantity $\left(Q_{i t}{ }^{3}\right)$, a measure of the age and technology mix of kilns in the market $\left(\mathrm{TECH}_{\mathrm{it}}\right)$, and prices for the input fuel (PFUEL $\left.\mathrm{PL}_{\mathrm{it}}\right)$ and electricity $\left(\mathrm{PELEC}_{i t}\right)$. These two price inputs represent, on average, $40 \%$ of variable costs. ${ }^{15}$

Since the analysis was across markets, some adjustment had to be made in the price equation for different capacities (Figure 18). Two markets may face identical demands, a situation that is depicted by the curve $D_{0}$. Yet one may have a capacity of 1 million tons per year and the other a capacity of 3 million tons per year. Very different prices would emerge. To account for this, quantity was divided by market total capacity (TOTCAP (T) $_{\text {) }}$. To account for any price variations that may arise because of market imperfections, a seller Herfindahl index $\left(\mathrm{HERF}_{\mathrm{it}}\right.$ ) was also added to the supply equation to provide: ${ }^{16}$

$$
P_{k}=\beta_{0}\left|\frac{Q_{t}^{S}}{\operatorname{TOTCAP}_{k}}\right|^{\beta_{1}} \text { TECH }_{k}^{\beta_{2}} \text { PELEC }_{k}^{\beta_{3}} \text { PFUEL }_{k}^{\beta_{4}} \text { HERF }_{k}^{\beta_{3}} e_{k}
$$

\section{DATA}

This analysis examined prices and quantities in 25 regional cement markets for 1972 through 1984. A total of 251 observations were included. Each of the 25 markets in this

${ }^{14}$ Higher unit costs could result from smaller-scale, older capital, and/or less-efficient technology.

15 Various issues of the Annual Survey of Manufactures.

${ }^{16}$ A Herfindahl index is calculated as the sum of the squared market shares. 


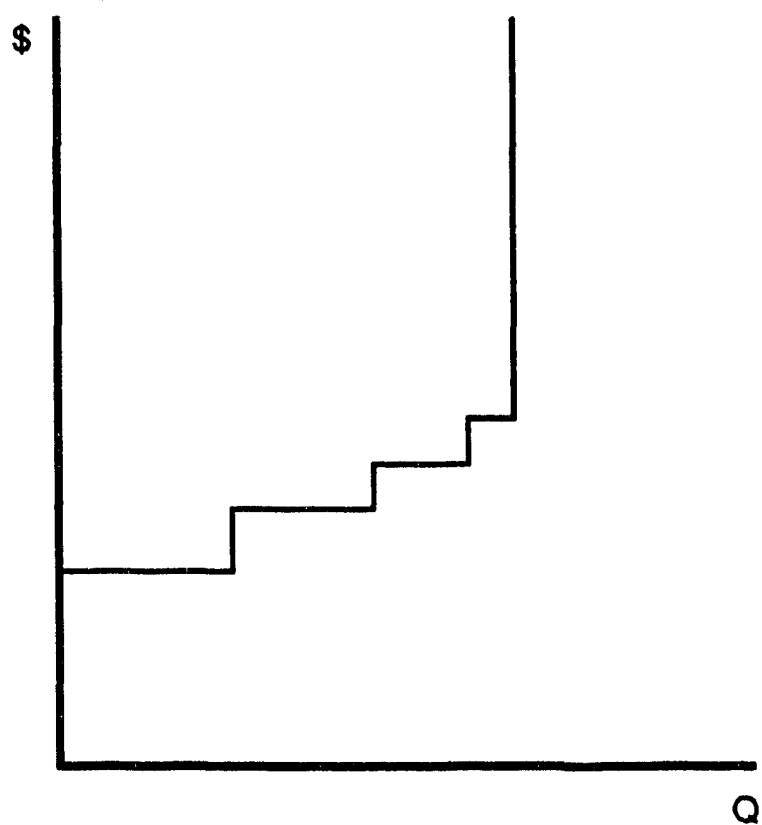

FIGURE 17 Step Function Supply Curve for Cement Production

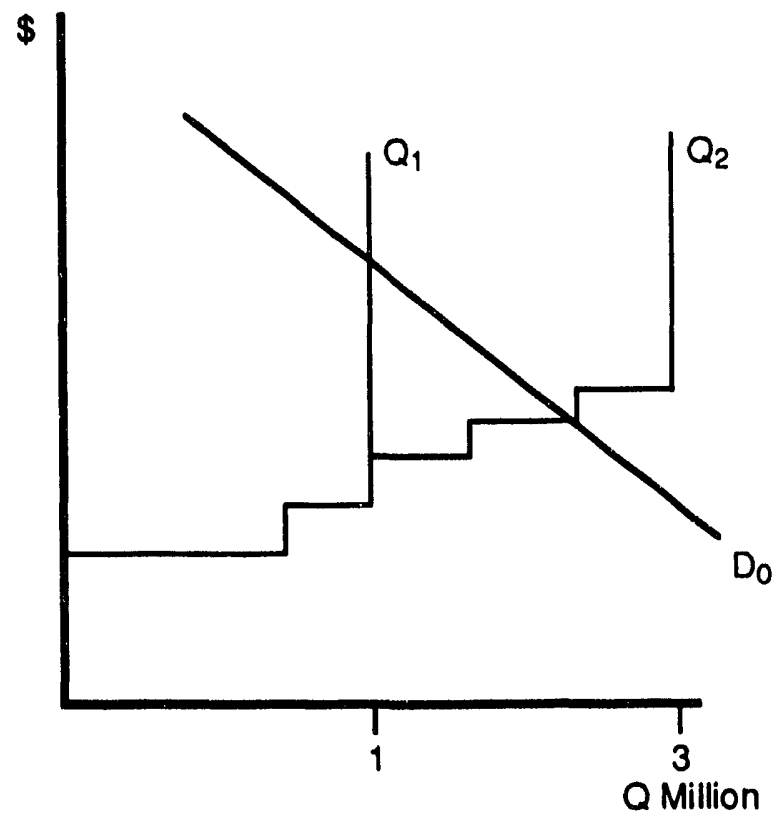

FIGURE 18 Demand and Supply for Alternative Capacities

analysis consisted of a major metropolitan area and all portland cement plants located within 200 miles of the central city. A list of the markets is shown in Table 16.

\subsubsection{Total Capacity (TOTCAP ${ }_{\text {it }}$ )}

The Portland Cement Association (PCA), in its Plant Information Summary, publishes yearly information on the capacity and location of practically all cement plants in the United States. This information makes it possible to identify all plants within each regional market. Total market capacity, in millions of tons, is the sum of plant capacities in the market.

\subsubsection{Price $\left(\mathbf{P}_{\mathrm{it}}\right)$}

The U.S Department of the Interior, in its Minerals Yearbook, publishes data on the value per ton of cement shipped, aggregated to either states or subregions of states. The values represent a transaction price. A market price is then calculated for each regional market in each year by weighing the price in each state within the region by the percentage of the region's capacity located in that state. The average price is then deflated by the producer price index (base $=1977$ ) to obtain an estimate of the real price per ton of cement.

To obtain the capacity weights, data from PCA's Plant Information Summary are used. From these data (described above), the percentage of a region's capacity located within 
TABLE 16 Regional Markets Used in the Analysis

\begin{tabular}{llll}
\hline Atlanta & Dallas & Minneapolis & Pittsburgh \\
Baltimore & Denver & New Orleans & St. Louis \\
Birmingham & Detroit & New York City & Salt Lake City \\
Boston & Houston & Oklahoma City & San Antonio \\
Chicago & Kansas City & Philadelphia & San Francisco \\
Cincinnati & Los Angeles & Phoenix & Seattle \\
Cleveland & & & \\
\hline
\end{tabular}

each state can be determined. These percentages become the weights in converting statelevel data to market-level data.

\subsubsection{Quantity $\left(\mathbf{Q}_{\mathrm{it}}\right)$}

The U.S. Department of the Interior, in its Minerals Yearbook, publishes data on the total value of current cement shipments and kiln capacities aggregated by state. For each state, the value of shipments is divided by capacity to obtain a shipments-to-capacity ratio. The PCA data are then used to form market shipments-to-capacity ratios from weighted state ratios. Finally, for each market, the shipments-to-capacity ratio is multiplied by market capacity to get a measure of total market shipments in millions of tons.

\subsubsection{Residential Construction Expenditures $\left(\mathbf{R E S}_{\mathbf{i t}}\right)$}

Data (in current dollars) on new residential construction expenditures, by city, are published by the U.S. Bureau of the Census in Housing Authorized by Building Permits and Public Contracts. These are deflated by the producer price index to obtain real values.

\subsubsection{Nonresidential Construction Expenditures $\left(\right.$ NRES $\left._{i t}\right)$}

Data (in current dollars) on nonresidential construction expenditures are obtained from the U.S. Bureau of the Census's The Construction Review. These figures are also deflated by the producer price index.

\subsubsection{Highway Construction Expenditures $\left(\mathrm{HWY}_{\mathrm{it}}\right)$}

Highway construction expenditures, in current dollars, for each market are obtained from the U.S. Bureau of the Census's City Government Finances and are deflated by the producer price index to obtain real values. 


\subsubsection{Personal Income (INC it $_{\text {) }}$}

Personal income data, by city, are obtained from various issues of the Survey of Current Business. Current-dollar values are measured in hundreds of millions of dollars. These are deflated by the producer price index to obtain real values.

\subsubsection{Price of Asphalt (PASPH ${ }_{i t}$ )}

State-level asphalt prices, in dollars per million Btu, are obtained from the Energy Price and Expenditure Data Report published by DOE. The state-level data are weighted by relative kiln capacities to get metropolitan-level data. These are deflated by the producer price index to obtain real values.

\subsubsection{Price of Electricity $\left(\right.$ PELEC $\left._{i t}\right)$}

State-level electricity prices for the industrial sector, in dollars per million Btu, are obtained from the Energy Price and Expenditure Data Report published by DOE. The state-level data are weighted by relative kiln capacities to get metropolitan-level data. These are deflated by the producer price index to obtain real values.

\subsubsection{Price of Fuel (PFUEI ${ }_{4 i}$ )}

Cement manufacturers predominantly use either coal or natural gas as kiln fuels. ${ }^{17}$ State-level prices for both coal and natural gas, in dollars per million Btu, are obtained from DOE's Energy Price and Expenditure Data Report. They are then weighted to obtain metropolitan-level prices. The PCA's Energy Report shows the yearly national relative use of coal and natural gas as kiln fuels. These yearly relative-use figures are shown in Table 17. The metropolitan-level prices for each type of fuel are weighted by their yearly relative uses to calculate a fuel price per million Btu. This figure is deflated by the producer price index to get a real fuel price.

\subsubsection{Technology $\left(\right.$ TECH $\left._{i t}\right)$}

The mix of technologies present in a market is proxied by the weighted average of the ages of kilns in a market. The weights are kiln capacities.

17 In 1979, for example, 92.8\% of fuel was either coal or natural gas (PCA 1980). 


\subsubsection{Herfindahl Index (HERF it $_{\text {) }}$}

Data from PCA are used to calculate market shares based on capacities. Market shares are squared and totaled to obtain Herfindahl indices.

\subsection{ESTIMATION AND RESULTS}

Iterative, nonlinear, three-stage least-squares estimation is used to estimate the simultaneous system specified in Equations 4 and 5. This technique controls for the simultaneity between prices and shipments and corrects for any crossequation correlation between the disturbances. Results of the analysis are shown in Table 18. The pseudo $R^{2} \mathrm{~s}$ for the quantity and price equations are 0.56 and 0.21 , respectively. ${ }^{18}$

Quantity (demand) equation results
TABLE 17 Re iative Fuel Use in the Cement Industry by Year (\%)

\begin{tabular}{|c|c|c|}
\hline Year & Coal & $\begin{array}{c}\text { Natural } \\
\text { Gas }\end{array}$ \\
\hline 1972 & 44.2 & 55.8 \\
\hline 1973 & 45.6 & 544 \\
\hline 1974 & 48.3 & 51.7 \\
\hline 1975 & 52.5 & 47.5 \\
\hline 1976 & 61.5 & 38.5 \\
\hline 1977 & 72.3 & 27.7 \\
\hline 1978 & 76.2 & 23.8 \\
\hline 1979 & 76.2 & 23.8 \\
\hline 1980 & 81.5 & 18.5 \\
\hline 1981 & 85.1 & 14.9 \\
\hline 1982 & 89.5 & 10.5 \\
\hline 1983 & 93.4 & 6.6 \\
\hline 1984 & 93.3 & 6.7 \\
\hline
\end{tabular}

Source: PCA, Energy

Report (various years). are shown in Table 18. The coefficient on price suggests that demand is either inelastic or perfectly inelastic. This result is reasonable. Residential and nonresidential construction expenditures have a statistically insignificant impact on the demand for cement. These two categories make up a meaningful proportion of the demand for cement. However, the proportion of these expenditures accounted for by cement is fairly small. ${ }^{19}$ They may therefore not be good direct measures of the demand for cement. Furthermore, it is not clear what percentage of the expenditures was actually made and what percentage was just budgeted in any year. The data probably lead actual construction expenditures. The length of the lead and its consistency over time and across regional markets are unknown. ${ }^{20}$

18 These are calculated as the squared correlation coefficient between the predicted and actual values.

19 The National Association of Home Builders estimates that cement makes up approximately $1 \%$ of the cost of a home. Only very large nonresidential construction projects, such as office buildings, use significant amounts of cement.

20 The model was estimated with residential and nonresidential construction expenditures lagged one and two periods. None of the coefficients on these variables were significant. 
TABLE 18 Results of Simultaneous Equation Analysis of Price and Quantity for the Cement Industry ${ }^{a}$

\begin{tabular}{|c|c|c|}
\hline Variable & $\begin{array}{c}\text { Quantity } \\
\left(\mathbf{Q}_{\mathrm{it}}\right)\end{array}$ & $\begin{array}{l}\text { Price } \\
\left(\mathbf{P}_{i t}\right)\end{array}$ \\
\hline Intercept & $\begin{array}{c}2.354 \\
(2.774)\end{array}$ & $\begin{array}{l}2.547^{b} \\
(0.266)\end{array}$ \\
\hline Price $\left(P_{i t}\right)$ & $\begin{array}{c}-0.678 \\
(0.822)\end{array}$ & -- \\
\hline Quantity $\left(Q_{i \sqrt{ }}\right.$ TOTCAP $\left.^{\text {it }}\right)$ & -- & $\begin{array}{l}0.525^{b} \\
(0.143)\end{array}$ \\
\hline $\begin{array}{l}\text { Residential construction } \\
\text { expenditures (RESCON } \\
\text { it })\end{array}$ & $\begin{array}{l}-0.165 \\
(0.114)\end{array}$ & -- \\
\hline $\begin{array}{l}\text { Nonresidential construction } \\
\text { expenditures }\left(\mathrm{NRES}_{\mathrm{tt}}\right)\end{array}$ & $\begin{array}{c}-0.070 \\
(0.125)\end{array}$ & -- \\
\hline $\begin{array}{l}\text { Highway construction } \\
\text { expenditures }\left(\mathrm{HWYCON}_{\mathrm{it}} \text { ) }\right.\end{array}$ & $\begin{array}{l}0.178^{b} \\
(0.067)\end{array}$ & -- \\
\hline Personal income $\left(\mathrm{INC}_{\mathrm{it}}\right)$ & $\begin{array}{l}0.340^{\mathrm{c}} \\
(0.150)\end{array}$ & -- \\
\hline Price of asphalt $\left(\mathrm{PASPH}_{\mathrm{it}}\right)$ & $\begin{array}{c}0.251^{\mathrm{c}} \\
(0.124)\end{array}$ & -- \\
\hline $\begin{array}{l}\text { Vintage (technology proxy) } \\
\left(\text { TECH }_{i t}\right)\end{array}$ & -- & $\begin{array}{l}(-0.011 \\
(0.037)\end{array}$ \\
\hline Electricity price $\left(\right.$ PELEC $\left._{i t}\right)$ & -- & $\begin{array}{l}0.059^{d} \\
(0.033)\end{array}$ \\
\hline Fuel price $\left(\right.$ PFUEL $_{\mathrm{it}}$ ) & -- & $\begin{array}{l}0.237^{b} \\
(0.050)\end{array}$ \\
\hline Herfindahl index $\left(\right.$ HERF $\left._{i t}\right)$ & -- & $\begin{array}{l}0.183^{c} \\
(0.045)\end{array}$ \\
\hline
\end{tabular}

a Standard error in parentheses.

b Statistically significant at $99 \%$ using two-tailed test.

c Statistically significant at $\mathbf{9 5 \%}$ using two-tailed test.

d Significantly significant at $90 \%$ using two-tailed test. 
The coefficient on highway construction expenditures is positive and significant. "The coefficient is an elasticity and also closely proxies the percentage of total demand for cement made up by highway construction. PCA publications indicate that the coefficient's magnitude is reasonable. ${ }^{21}$

Personal income, as an indicator of general economic activity, has a significant impact on demand. The coefficient on the price of asphalt shows a fairly high cross-price elasticity of demand. Every $4 \%$ increase in the real price of asphalt increases the demand for portland cement by $1 \%$.

Price (supply) equation results are also shown in Table 18 . Every $1 \%$ increase in quantity relative to capacity increases price by roughly $0.5 \% .^{22}$ Vintage as a proxy for technology has a statistically insignificant effect on price. ${ }^{23}$ This result indicates that prices. do not respond to technology-related cost savings. If cost savings occur in newer vintages, they influence profits more than price in this industry.

Electricity and fuel prices have the expected effects on price, although the coefficient on the price of electricity is significant at just over the $90 \%$ confidence level. Every $1 \%$ increase in the price of electricity increases the price of cement by $0.059 \%$. Every $1 \%$ increase in the price of fuel increases the price of cement by $0.237 \%$. The magnitude of the electricity coefficient is reasonable. The fuel coefficient is perhaps a little high. ${ }^{24}$ The coefficient on the Herfindahl index suggests that higher levels of market concentration lead to higher prices.

\subsection{CARBON TAX IMPLICATIONS}

A carbon tax will have two impacts on cement pricing. First, it will increase general energy costs. Second, because cement production is energy intensive, it will increase energy input costs for the industry. Table 19 shows the estimated price increase per million Btu (in current dollars and real 1977 dollars) for coal, natural gas, and electricity as a result of a $\$ 25$ and $\$ 100$ tax. Under a $\$ 100$ tax, for example, the price of 1 million Btu of electricity would increase by $\$ 6.59$ (in current dollars) or $\$ 3.59$ (in 1977 real dollars).

Cement production also results in carbon emissions that are not caused by energy use. The cost of producing cement will therefore have to increase because of the tax.

21 Exhibit 25 in PCA (1984) indicates that on average, in the years 1978 through $1982,18.8 \%$ of cement demand was for street and highway use.

22 Note that this coefficient is the inverse of the supply elasticity. Hence, the elasticity of supply is 1.9 , more elastic than would be expected.

${ }^{23}$ Das (1992) suggests that kiln efficiency affects relative input use. Specifications to account for this hypothesis were tried, and vintage still had no impact on price.

24 Various issues of the Annual Survey of Manufactures show that the average ratios of purchased electricity to shipments and purchased fuel to shipments equal $7 \%$ and $17 \%$, respectively. 
TABLE 19 Impact of Carbon Taxes on Input Prices and Cement Production Costs

\begin{tabular}{|c|c|c|}
\hline \multirow[b]{2}{*}{ Unit of Measure } & \multicolumn{2}{|c|}{$\begin{array}{l}\text { Resulting Cost } \\
\text { Increase per } \\
\text { Carbon Tax }\end{array}$} \\
\hline & $\$ 25 / t$ & $\$ 100 / t$ \\
\hline \multicolumn{3}{|l|}{$\begin{array}{l}\text { Per } 10^{6} \text { Btu } \\
\text { In nominal } \$\end{array}$} \\
\hline Coal & 0.64 & 2.55 \\
\hline Natural gas & 0.36 & 1.45 \\
\hline Electricity & 5.33 & 6.59 \\
\hline \multicolumn{3}{|l|}{ In real $1977 \$$} \\
\hline Coal & 0.35 & 1.39 \\
\hline Natural gas & 0.20 & 0.79 \\
\hline Electricity & 2.90 & 3.59 \\
\hline \multicolumn{3}{|c|}{$\begin{array}{l}\text { Per ton of cement based on } \\
\text { tax's impact due to cement } \\
\text { carbon emissions alone }\end{array}$} \\
\hline In nominal $\$$ & 3.25 & 13.00 \\
\hline In real $1977 \$$ & 1.77 & 7.08 \\
\hline
\end{tabular}

Table 19 shows the nominal and real cost increases resulting from a $\$ 25$ and $\$ 100$ tax. Under a $\$ 100$ tax, carbon emissions from cement production would force costs per metric ton up by $\$ 13.00$ (in current dollars) or $\$ 7.08$ (in 1977 real dollars).

Average values across the market in 1984 (the last year for which data were available) were used to estimate the impact of a carbon tax on the cement industry. ELEC $_{84}{ }^{\text {TAX }}$ and FUEL ${ }_{84}{ }^{\text {TAX }}$ represent the effect of a carbon tax on electricity prices and on fuel prices. ${ }^{25}$ The impact of the carbon tax on production costs due to cement carbon

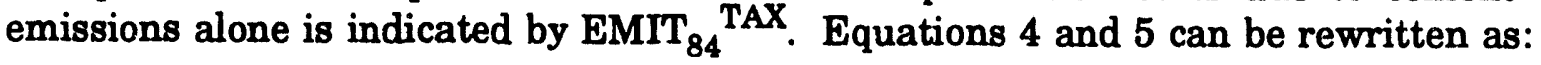

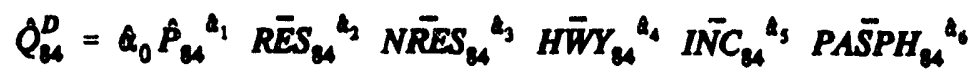

25 Recall that the price of fuel is a weighted average of the price of coal and natural gas. The actual mix that occurred in 1984 is maintained when the effect of the carbon tax on coal and natural gas prices is translated into fuel prices. 


$$
\begin{aligned}
\hat{P}_{84}= & \hat{\beta}_{0}\left(\frac{\hat{Q}_{84}^{S}}{\operatorname{TOT}_{\bar{C} A P_{84}}^{S}}\right)^{\hat{\beta}_{1}} T E \bar{C} H_{84}^{\beta_{2}}\left(P E \bar{L} E C_{84}+E L E C_{84}^{\text {IAX }}\right)^{\beta_{3}}\left(P F \bar{C} E L_{84}+F U E L_{84}^{T A X}\right)^{\beta_{4}} H \overline{E R} F_{84}^{\beta_{3}} \\
& +E M I T_{84}^{T A X}
\end{aligned}
$$

Equations 5 and 6 can be solved simultaneously for equilibrium prices and quantities that reflect the carbon tax. ${ }^{26}$

Table 20 shows the estimated price per ton of cement (in 1977 and 1990 dollars) under no carbon tax and a tax of $\$ 25$ and $\$ 100$. Under no carbon tax, the real 1977 price per ton of cement would be $\$ 30.61$. Under a $\$ 100$ tax, the price of a ton of cement would increase to $\$ 40.59$. In 1:990 dollars, those prices would be $\$ 56.20$ and $\$ 74.52$, respectively. In 1990 dollars, a $\$ 100$ cax would increase prices by $\$ 18.32$.

Table 20 also shows the percentage increases in the price of cement that would result from the carton tax. A $\$ 25$ tax would increase the price of cement by 9.9\%. A $\$ 100$ tax would increase the price of cement by $32.6 \%$. Prices in this industry would be significantly affected by a carbon tax.

The third section of Table 20 shows the impact of the carbon tax on market quantity. Under no tax, the equilibrium quantity would be 3.35 million tons. Under a $\$ 25$ tax, the

TABLE 20 Prices of Cement and Quantities Sold before and after Carbon Taxes

\begin{tabular}{lccc}
\hline & & \multicolumn{2}{c}{ Carbon Tax } \\
\cline { 4 - 5 } \multicolumn{1}{c}{ Parameter } & $\begin{array}{c}\text { No Carbon } \\
\text { Tax }\end{array}$ & $\$ 25 / \mathrm{t}$ & $\$ 100 / \mathrm{t}$ \\
\hline $\begin{array}{l}\text { Predicted price } \\
\text { per ton of cement } \\
\quad(1977 \$)\end{array}$ & & & \\
$\quad(1990 \$)$ & 30.61 & 33.64 & 40.59 \\
& 56.20 & 61.76 & 74.52 \\
$\begin{array}{l}\text { Increase in price } \\
\text { from no carbon tax (\%) }\end{array}$ & & 9.9 & 32.6 \\
$\begin{array}{l}\text { Resulting quantities } \\
\text { (10 }\end{array}$ & 3.35 & 3.14 & 2.77 \\
$\begin{array}{l}\text { Decrease in quantity } \\
\text { from no carbon tax }(\%)\end{array}$ & & & \\
\hline
\end{tabular}

${ }^{26}$ In solving Equations 6 and 7, both $Q$ and $P$ are quite nonlinear. A numerical technique was used to soive for the equilibrium levels. 
quantity would decrease by $6.2 \%$, to 3.14 million tons. Under a $\$ 100$ tax, the quantity would decrease by $17.3 \%$, to 2.77 million tons. This decrease would result in a corresponding decrease in $\mathrm{CO}_{2}$ emissions as a result of lower production.

\subsection{CONCLUSION}

Current policy discussions focus on the imposition of a carbon tax to reduce greenhouse gas emissions. A carbon tax might seriously affect certain industries. One such industry is the cement industry. The cement industry is a heavy user of fossil fuels, and the cement production process emits a significant amount of carbon. It is important to analyze this industry in light of proposed carbon taxes.

This analysis shows that a carbon tax could have a very significant impact on prices in this industry. A tax of $\$ 100$ per metric ton of carbor would increase cement prices by $32.6 \%$. Given the prolific use of cement by the construction industry and this industry's important position in the economy, such a tax could have significant consequences on the economy as a whole. 


\section{CONCLUSIONS}

This report focuses on energy use and carbon emissions in three subsectors of the stone, clay, and glass industry (SIC 32). A conservation supply curve (CSC) analysis by the LIEF model found that opportunities for reducing energy use in all three subsectors are similar but quite modest. In a subsequent analysis, statistical techniques were applied to the largest and most energy intensive of the three subsectors: the cement industry. The following conclusions focus on the cement industry.

Current policy discussions concentrate on the imposition of a carbon tax to reduce greenhouse gas emissions. Although a carbon tax could be the most efficient way to reduce carbon emissions, it might seriously affect certain industries. One such industry is the cement industry. This industry is a heavy user of fossil fuels, and the process of producing cement creates a significant amount of carbon emissions. It is important to specifically analyze this industry in light of proposed carbon taxes.

Table 21 compares the results from the LIEF model analysis and a plant-level statistical analysis of how a carbon tax would affect energy use in the cement industry. The LIEF analysis and plant-level analysis show very similar results with respect to electricity use, but results with respect to fossil fuel use vary widely. The LIEF analysis explicitly accounts only for conservation opportunities; remaining declines in energy use are attributed to technology trends. In principle, the plant-level analysis does the same. However, the plant-level analysis draws from data on regional variations in energy prices and plant-level energy use. If there are any options to adjust the amount of energy used in the cement production process as a result of local conditions and energy prices, these adjustments are reflected in the plant-level data, but they are not reflected in the aggregate LIEF data. Therefore, the estimate of energy responsiveness from the plant-level analysis should be at least as large as that from the aggregate approach and should tend to be larger, ceteris paribus. Even though the plant-level analysis shows more energy responsiveness, the elasticities are not large.

TABLE 21 Impact of a $\$ 100$ Carbon Tax on Energy Use in the Cement Industry

\begin{tabular}{lcccccc}
\hline & \multicolumn{2}{c}{ Energy } & & \multicolumn{3}{c}{ Variable Costs (expenditure share) } \\
\cline { 2 - 3 } \cline { 6 - 7 } Analysis & Elestricity & Fossil Fuel & & Electricity & Fossil Fuel & Average Variable \\
\hline LIEF & $-9 \%$ & $-15 \%$ & & NA $^{\mathrm{a}}$ & NA & NA \\
Plant level & $-13 \%$ & $-52 \%$ & & $+35 \%$ & $+35 \%$ & $+26 \%$ \\
\hline
\end{tabular}

NA = not available. 
The LIEF and the plant-level analyses both indicate there is a nonlinear relationship between the carbon tax and any associated energy conservation. LIEF predicts that the impact of a $\$ 25$ tax would be about half that of a $\$ 100$ tax. The plant-level analysis exhibitseven more nonlinearity; a $\$ 25$ tax would achieve $60 \%$ to $70 \%$ of the reduction in energy use that would be obtained under a $\$ 100$ tax. Both analyses suggest strong diminishing returns to the level of the carbon tax.

The analysis on interfuel substitution shows that additional gains in reducing carbon loading are possible in the cement industry. This industry is a heavy user of coal but could switch to gas. The statistical results suggest that an $11 \%$ reduction in the average carbon content of fossil fuel would occur under a $\$ 100$ tax. This additional reduction would not be entirely additive, since fuel switching lessens the impact of the carbon tax somewhat. In other words, the industry might achieve the $11 \%$ reduction as a result of switching fuel, but the resulting lower tax burden would lessen the incentive to take overall conservation measures (i.e., the predicted reduction in fossil fuel use from either analysis would be somewhat lower).

The supply and demand analysis shows that a carbon tax could have a very significant impact on prices in the cement industry. A $\$ 100$ tax would increase cement prices by more than $32 \%$. Given the prolific use of cement in construction and the construction industry's important position in the economy, such a price increase could have significant consequences on the economy as a whole. Demand for cement would fall by more than $17 \%$. While this decreased demand would result in direct reductions in carbon emissions, the reduction would occur at the expense of the business and employees of the marginal cement producers in the affected markets.

This supply and demand analysis does not allow for interaction of the carbon tax with economic activity or with other sectors. None of the approaches considers the effect of the tax on intersectoral competition. However, this issue is not critical for most of the SIC 32 products, because the relative impact of the tax on total costs is surprisingly small except in the cement industry (see Table 2). Nonetheless, even a small relative cost increment might be important in the food and beverage container industry, affecting the intense competition among the glass, paper composite, plastic, aluminum, and steel industries. Analysis of this issue is beyond the scope of this study.

If one assumes that the effects of the fuel reductions found in the LIEF and plantlevel analyses are independent of the impacts on carbon emissions from fuel substitution, and if one assumes that the forecasted reduction in cement demand does not affect the industry average energy intensity or fuel mix, these effects combined would reduce overall $\mathrm{CO}_{2}$ emissions in the cement industry. Under a $\$ 100$ tax, emissions from fossil fuel use would decrease 35\% (LIEF) to 63\% (plant-level analysis). Indirect emissions from electricity use would decrease $24 \%$ (LIEF) to 28\% (plant-level analysis). Process emissions would decrease $17 \%$. In 1988, the relative $\mathrm{CO}_{2}$ emissions from burning fossil fuels, electricity, and the process were $32 \%, 8 \%$, and $59 \%$, respectively, yielding a total $\mathrm{CO}_{2}$ reduction of between $24 \%$ and 33\% under a $\$ 100$ tax. Table 22 summarizes the $\mathrm{CO}_{2}$ emission reductions that would be achieved under the $\$ 25$ and $\$ 100$ tax the basis of these assumptions. 
TABLE 22 Impact of Carbon Taxes on $\mathrm{CO}_{2}$ Emissions in the Cement Industry

\begin{tabular}{|c|c|c|c|c|c|}
\hline \multirow[b]{2}{*}{$\begin{array}{c}\text { Carbon } \\
\text { Tax }\end{array}$} & \multirow[b]{2}{*}{ Analysis } & \multicolumn{4}{|c|}{$\begin{array}{c}\mathrm{CO}_{2} \text { Emission Reduction } \\
\left(10^{6} \mathrm{t} \text { of } \mathrm{C}\right) \text { from: }\end{array}$} \\
\hline & & $\begin{array}{c}\text { Reduced } \\
\text { Electricity } \\
\text { Use }\end{array}$ & $\begin{array}{l}\text { Reduced } \\
\text { Fossil } \\
\text { Fuel Use }\end{array}$ & $\begin{array}{l}\text { Reduced } \\
\text { Demand }\end{array}$ & Total \\
\hline$\$ 25 / t$ & $\begin{array}{l}\text { LIEF } \\
\text { Plant level }\end{array}$ & $\begin{array}{l}0.17 \\
0.27\end{array}$ & $\begin{array}{l}1.18 \\
2.76\end{array}$ & $\begin{array}{l}0.75 \\
0.75\end{array}$ & $\begin{array}{l}2.10 \\
3.79\end{array}$ \\
\hline$\$ 100 / t$ & $\begin{array}{l}\text { LIEF } \\
\text { Plant level }\end{array}$ & $\begin{array}{l}0.42 \\
0.49\end{array}$ & $\begin{array}{l}2.41 \\
4.34\end{array}$ & $\begin{array}{l}2.14 \\
2.14\end{array}$ & $\begin{array}{l}4.97 \\
6.98\end{array}$ \\
\hline
\end{tabular}




\section{REFERENCES}

Boyd, G.A., et al., 1991a, Sectoral Electricity and Fossil Fuel Demand in U.S. Manufacturing: Development of the Industrial Regional Activity and Energy Demand (INRAD) Model, ANL/EAIS/TM-35, Argonne National Laboratory, Argonne, Ill.

Boyd, G.A., et al., 1991b, unpublished information, Argonne National Laboratory, Argonne, Ill.

Considine, T.J., 1989, "Separability, Function Form and Regulatory Policy in Models of Interfuel Substitution," Energy Economics, pp. 82-94, April.

Das, S., 1992, "A Micro-Economic Model of Capital Utilization and Retirement: The Case of the U.S. Cement Industry," Review of Economic Studies 59:277-297.

DOE, 1989, A Compendium of Options for Government Policy to Encourage Private Sector Responses to Potential Climate Change, DOE/EA-0102, U.S. Department of Energy, Washington, D.C.

DOE, 1991, Limiting Net Greenhouse Gas Emissions in the United States: Volume I, Energy Technologies, Volume II, Energy Responses, DOE/PE-0101, R. Bradley et al. (editors), U.S. Department of Energy, Washington, D.C.

DOE, 1991/1992, Technical Annex 2. Integrated Analysis Supporting the National Energy Strategy: Methodology, Assumptions and Results, DOE/S-0086P, U.S. Department of Energy, Washington, D.C.

Edmunds, J., and J. Reilly, 1983, "Global Energy and $\mathrm{CO}_{2}$ to the Year 2050," The Energy Journal 4:21-47.

EIA, 1988, Manufacturing Energy Consumption Survey: Fuel Switching, 1985, DOE/EIA0515(85), U.S. Department of Energy, Energy Information Administration, Washington, D.C.

EIA, 1990, Energy Consumption and Conservation Potential: Supporting Analysis for the National Energy Strategy, SR/NES/90-02, U.S. Department of Energy, Energy Information Administration, Washington, D.C.

EIA, 1991, Changes in Energy Intensity in the Manufacturing Sector 1980-1988, DOE/EIA-0552(80-88), U.S. Department of Energy, Energy Information Administration, Washington, D.C.

EPA, 1990, Policy Options for Stabilizing Global Climate, report to Congress, D.A. Lashof and D.A. Tirpak (editors), U.S. Environmental Protection Agency, Washington, D.C., Dec.

Goulder, L.H., 1992, "Carbon Tax Design and U.S. Industry Performance," vol. 6 in Tax Policy and the Economy, National Bureau of Economic Research.

Herman, R.S., et al., 1989, "Dematerialization," in Technology and Environment, J.H. Ausubel (editor), National Academy Press, Washington, D.C., pp. 50-69. 
Hogan, W., and D. Jorgenson, 1991, "Productivity Trends and the Cost of Reducing $\mathrm{CO}_{2}$ Emissions," The Energy Journal 12(1):68-85.

Hwang, R., and M.H. Ross, 1992, Reducing Energy Demand and Carbon Emissions from U.S. Manufacturing, draft report, Lawrence Berkeley Laboratory, Berkeley, Calif.

Koomey, J., et al., 1992, An Assessment of Future Energy Use and Carbon Emissions from U.S. Residences, draft report, Lawrence Berkeley Laboratory, Berkeley, Calif.

Manne, A., and R. Richels, 1990, "CO $\mathrm{CO}_{2}$ Emission Limitations: An Economic Cost Analysis for the United States," The Energy Journal 11(2):74.

Morrison, C., 1988, "Quasi-Fixed Inputs in U.S. and Japanese Manufacturing: A Generalized Leontief Restricted Cost Function Approach," The Review of Economics and Statistics, pp. 275-287.

NEA, 1988, National Energy Accounts 1958-1985, prepared by Jack Faucett Associates for the U.S. Department of Commerce, Washington, D.C.

Nordhaus, W., 1991, "The Cost of Slowing Climate Change: A Survey," The Energy Journal 12(1):37-65.

NRC, 1990, Confronting Climate Change: Strategies for Energy Research and Development, National Research Council, Washington, D.C., published by National Academy Press, Washington, D.C.

OTA, 1991, "The Manufacturing Sector," chap. 6 in Changing by Degrees: Steps to Reduce Greenhouse Gases, U.S. Congress, Office of Technology Assessment, Washington, D.C.

PCA, 1980 and various years, Energy Report, Portland Cement Association, Skokie, Ill.

PCA, 1984, The U.S. Cement Industry: An Economic Report, third edition, Portland Cement Association, Skokie, 111 .

PCA, various years, Plant Information Summary, Portland Cement Association, Skokie, Ill.

Ross, M.H., 1991, "The Potential for Reducing the Energy Intensity and Carbon Dioxide Emissions in U.S. Manufacturing," in The Energy Sourcebook: A Guide to Technology, Resources, and Policy, R. Howes and A. Fainberg (editors), American Institute of Physics, New York, N.Y.

Ross, M.H., and R. Hwang, 1992, A Model for Long-Term Industrial Energy Forecasting, LBL-31861, Lawrence Berkeley Laboratory, Berkeley, Calif.

Shepard, R.W., 1970, Theory and Cost of Production Functions, first edition, D.G. Kuhn (editor), Princeton Studies in Mathematical Economics, Princeton University Press, Princeton, N.J.

U.S. Bureau of the Census, 1977, Census of Transportation, Washington, D.C.

U.S. Bureau of the Census, various years, The Construction Review, Washington, D.C. 
U.S. Bureau of the Census, various years, Housing Authorized by Building Permits and Public Contracts, City Government Finances, Washington, D.C.

U.S. Bureau of the Census, various years, City Government Finances, Washington, D.C.

U.S. Department of Energy, various years, Energy Price and Expenditure Data Report, Washington, D.C.

U.S. Department of the Interior, various years, Minerals Yearbook, Washington, D.C.

Walfridson, B., 1987, Dynamic Models of Factor Demand: An Application to Swedish Industry, Ph.D. dissertation, University of Gothenberg, Gothenberg, Sweden.

Williams, R.H., et al., 1987, "Materials, Affluence, and Industrial Energy Use," Annual Review of Energy 12:99-144. 

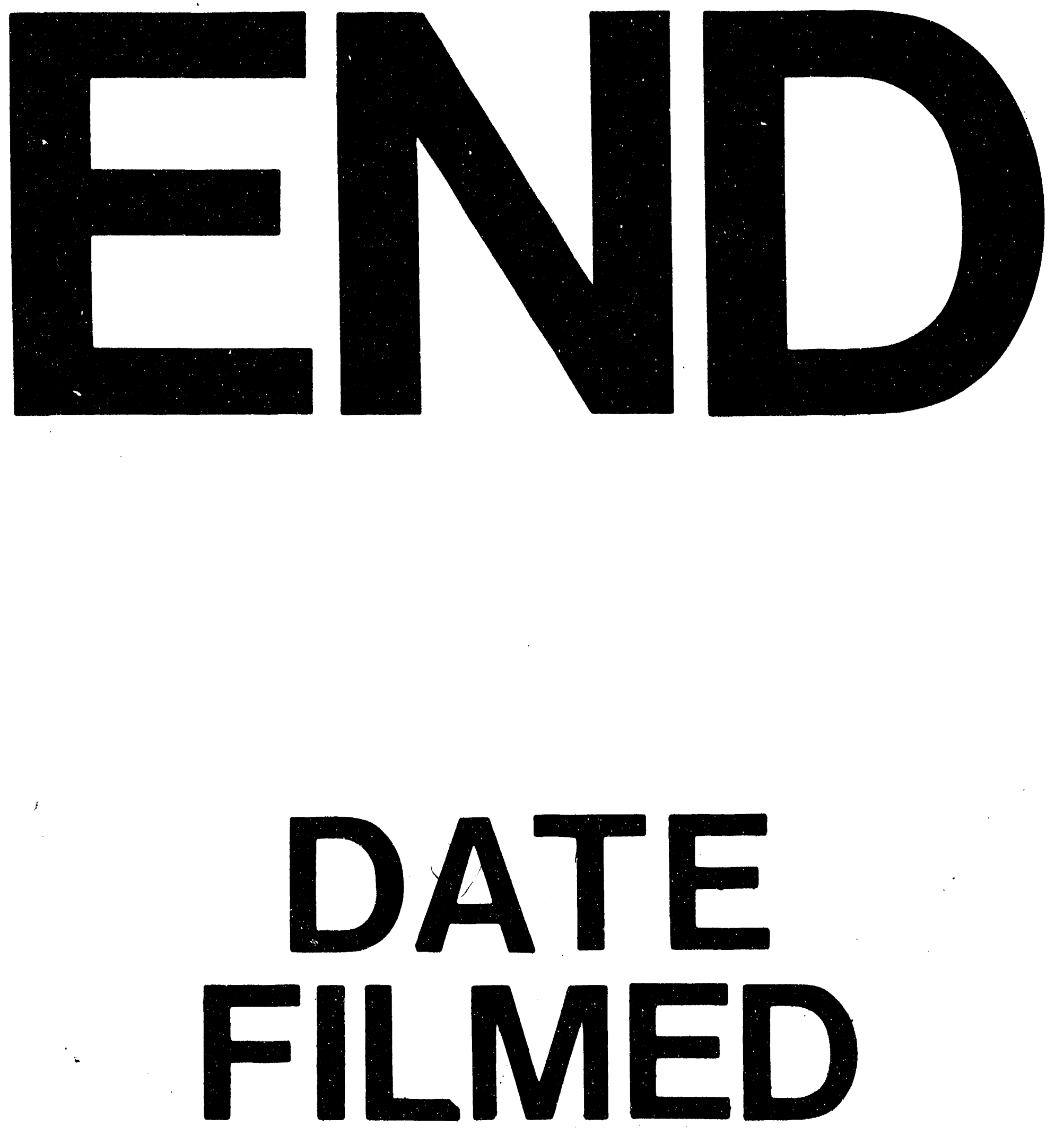

1

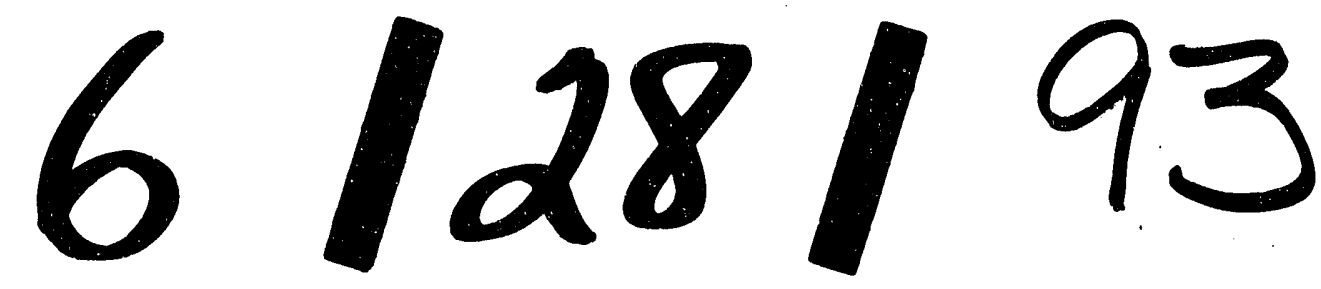


